\title{
Bartoneliasis. Fiebre Verrucosa del Guáitara
}

\author{
Luis Patiño-Camargo
}

Rev. Acad. Colomb. Cienc. Ex. Fis. Nat. 1951, 8 (31): 329-343.

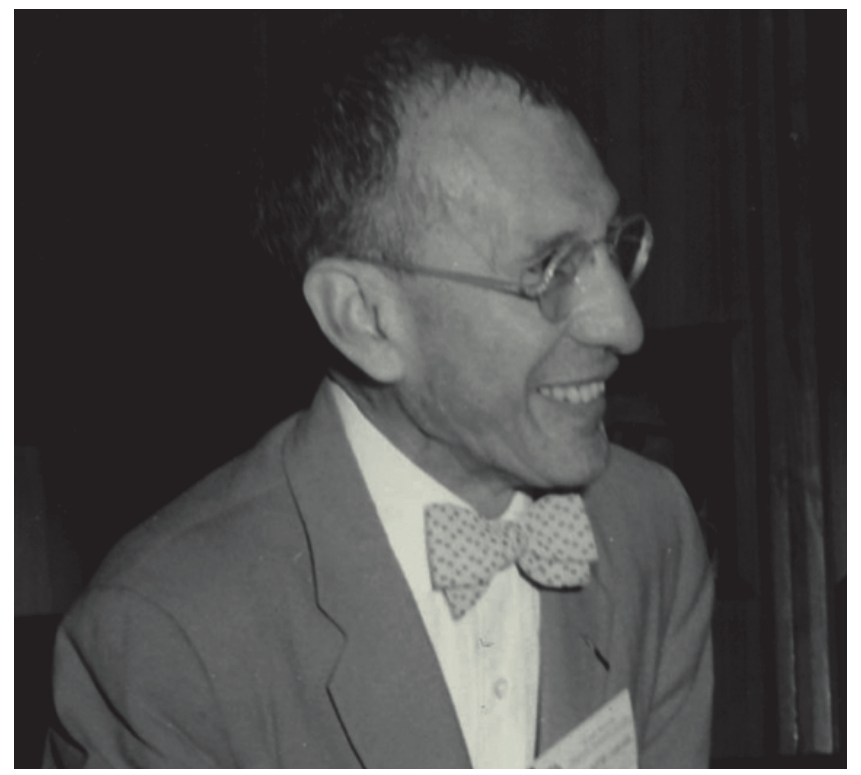

Doctor Luis Patiño Camargo (1891-1978). XII Reunión del Consejo Directivo de la OPS, agosto 20, 1960

Nacido en Iza, Boyacá, bachiller del Colegio Mayor del Rosario, donde fue colegial; se graduó en medicina de la Universidad Nacional de Colombia en 1922, con una tesis sobre la etiología del tifo exantemático. Inició su carrera docente en la misma Universidad Nacional en 1932, hasta llegar a profesor titular en la cátedra de Medicina Tropical. En 1937 publicó su célebre trabajo sobre " $\mathrm{La}$ fiebre petequial de Tobía", primer foco de rickettsiosis en Colombia. Ocupó diferentes cargos entre otros: Director Nacional de Higiene, director del Instituto Federico Lleras de Investigación Médica y director del Ministerio de Salud. Fue miembro de la Academia Nacional de Medicina - de la cual fue su presidente en 1945-, miembro de la Academia de Lengua y miembro de número de la Academia Colombiana de Ciencias Exactas, Físicas y Naturales. Luego de una gran trayectoria académica y de servicio público, el doctor Patiño se retiró a su hacienda Gouta (Iza) donde murió.

Información suplementaria disponible en: http://www.accefyn. org.co/sp/academicos/Silla_17_Luis_Patinho_Camargo.htm
El Ministerio de Higiene preocupado por la alarmante presencia de fiebres mortales en el sur del país desde 1936, comisionó en 1939 al doctor Luis Patiño Camargo para investigar dicho brote en el departamento de Nariño. Miles de casos de fiebres con crecimientos verrugosos se presentaron en habitantes de poblados en los valles de los afluentes del rio Patía, como en El Guáitara, lo que condujo la pesquisa a un paciente de Sandoná, en quien el 18 de enero se identificó Bartonella en sangre como el posible agente causal. En 1951 el doctor Patiño publicó un artículo de revisión con sus hallazgos y de otros investigadores colombianos sobre los trabajos en bartoneliasis o verruga peruana en Colombia. En el artículo describió desde los antecedentes históricos en los pueblos Incas y la concepción mágico-religiosa de la enfermedad, hasta llegar a la descripción geo-demográfica de las regiones afectadas, y al análisis de su epidemiologia y mortalidad. El doctor Patiño continuó con la descripción de la sintomatología desde su etapa aguda, hemática generalizada o septicemia del mal, hasta el periodo verrucomatoso o fase histiode, en donde señalaba que "la erupción (verruga) es la resultante del esfuerzo del retículo endotelio en encarcelar el virus y destruirlo"; esta fase mostrada mediante fotos de niños y adultos con lesiones verrugosas. El diagnóstico por laboratorio lo ilustró con imágenes de extendido de sangre con Bartonella, y fotos de modelos de inoculación en primates y curíes. En el texto discutió su patogénesis con ejemplos de estudios histológicos de paciente y primates, estos últimos infectados con tejidos verrugosos o con extractos de insectos como Phlebotomus y piojos, posibles vectores de la enfermedad. Finalmente, el doctor Patiño, anotó las recomendaciones al Estado para la mejora de las condiciones de vida en la región.

John M. González MD, PhD

Miembro Correspondiente

Con la colaboración del doctor José Félix Patiño Restrepo 


\section{BARTONELIASIS}

FIEBRE VERRUCOSA DEL GUAITARA (*)

LUIS PATIÑO - CAMARGO

Catedrático de Medicina Tropical de la Universidad Nacional

Sinónimos. - En Colombia al descubrirla diósele (4) a esta dolencia los siguientes nombres: Bartonellosis, Fiebre verrucosa del Guaitara y Verruga, análoga a la enfermedad de Carrión, Fiebre de Oroya y Verruga Peruana.

Definición. - Es la Bartoneliasis colombiana una enfermedad infecciosa retículo endotelial, específica, determinada por la Bartonella bacilliformis, inoculable y transmisible, clínicamente caracterizada por fiebre irregular, dolores reumatoides, anemia pseudo-perniciosa y terminada por erupción verrugosa.

Historia. - La Bartoneliasis humana en Colombia, fue descubierta y diagnosticada clínicamente por Patiño-Camargo (4) el 16 de enero de 1939 en pacientes febricitantes y verrugosos del Hospital de Sandoná y el diagnóstico clínico fue comprobado por hallazgo de la Bartonella en la sangre de un febricitante en período inicial, en la tarde del día 18 (**). La enfermedad en forma epidémica con mortalidad elevada, venía siendo motivo de grave preocupación pública desde 1936 y había recibido del pueblo numerosos apelativos: peste, peste negra, bubas, tifo, perniciosa, fiebre de Ancuya. Y los diagnósticos clínicos estaban divididos entre paludismo, tifoidea y leishmaniasis.

Todo lo observado hace pensar que es enfermedad autóctona y que vivió inadvertida de tiempo inmemorial, en los hondos valles del macizo de los Andes, tronco de las cordilleras colombianas, analógicamente a lo observado con el Sirki quechua de

(*) Trabajo académico lédo en la sesión del 7 de octubre de 1942 en la Academía Nacional de Medicina de México y publicado en la Gaceta Médica de México, D. F. tomo LXXiII, No 5 , octubre de 1943 .

Por ser prácticamente desconocido en Colombia se publica con algunas notas en la Revista, imaginando que los datos que encierra pudieran llegar a ser útiles a investigadores nacionales en estudios futuros.

(**) El orden cronologico del proceso según los archivos del Ministerio de Higiene, es como sigue: Enero 16 de 1939: el autor en comisión del Ministerio de Higiene hace el diagnostico de Bartoneliasis humana en pacientes febricitantes y verrucomatosos del hospital de Sandona, presentados por el doctor Raúl Jaramillo. Enero 17: Búsqueda infructuosa de Bartonellas en los mismos pacientes. Enero 18: Hallazgo de Bartonellas abundantes en la sangre de M. T. A., enfermo que traen ese día al hospital al comienzo de la fiebre. Enero 19 y 20: Viajes a Ancuya y Consacá para verifiear contrapruebas y comprobaciones en otros pacien. tes y comunicaciones telegráficas reservadas al Ministerio de Higiene. Enero 21: Informe verbal a los doctores Carlos Vela, Secretario de Higiene de Nariño; Raúl Jaramillo, Médico de Sandoná; Manuel Garzón, de Ancuya; Marcial Portilla, de Samaniego y Hernando Groot y ante los revisores de Sanidad señores Burbano y Rodriguez, del diagnostico clínico y microscópico, en el hospital de Sandoná. Comunicaciones telegraficas a la Facultad de Medicina, Academia y Ministerio de Higiene. Enero 22: Comunicacion verbal y discusión del diagnostico con el Colegio Médico de Pasto, en sesión presidida por el doctor Julio Moncayo Candia. las sierras peruanas. Cataclismos geológicos y calamidades humanas la despertaron y la sacaron de su retiro para echarla sobre poblaciones no inmunes. La enfermedad fue en sus comienzos sólo de campos y poblaciones nariñenses de clima medio. Posteriormente se ha extendido hacia el norte sobre los municipios limítrofes del Cauca. En Bogotá y Cali han ocurrido defunciones de casos procedentes de Nariño.

Los focos de Bartoneliasis humana en América. En los pueblos del Imperio Inca, sobre las quiebras y valles de la vertiente pacífica de los Andes peruainos, denominábase Sirki (5) una enfermedad eruptiva considerada por los naturales como propia de tales tierras. La primera expedición de los conquistadores españoles al mando de Pizarro, fue diezmada en Cuaque, hoy de la provincia de Manabí (Ecuador), el año de 1531, por una mortífera enfermedad febril, con dolores reumatismales y erupciones, designada "La Berruga" por historiadores y cronistas (6).

El antiquísimo memorial Tecpan Atitlan, menciona una dolencia de la región montañosa de Guatemala llamada Tlacaconanoatil por los aborígenes y que verosímilmente es la verruga, si se toma en cuenta que hacia 1522 y 1576 acaecieron entre los invasores castellanos mortíferas epidemias, apellidadas por historiadores y cronistas, "Bubas" (7). $\mathrm{Y}$ es noción elemental que la buba, pian o fram. buesa, sólo excepcionalmente es causa de muerte.

Comunicaciones oficiales (8-9) posteriores al hallazgo de Nariño, informan de focos de verruga encontrados en Loja, Guayaquil y Zumba (Ecuador). En consecuencia, hay tres focos ciertos de bartoneliasis humana en América: en el Perú, Ecuador y Colombia, extendidos desde 2 grados de latitud norte a 13 grados de latitud austral, un probable foco inadvertido en Guatemala $\mathrm{y}$ muchas zonas andinas con ambiente propicio para albergar calladamente la enfermedad.

Nota geográfica. - Hállase el foco colombiano en los Departamentos de Nariño y Cauca cerca a la frontera con el Ecuador, al norte de la línea equinoxial y junto al mar. La primitiva zona epidémica está en el macizo de la Cordillera de los Andes, en medio de los volcanes Azufral, Cumbal, Galeras y Doña Juana, sobre las escarpadas vertientes de los ríos Mayo, Juanacatú, Juanambú, Sapuyes, Pacual y Guáitara, torrentosos afluentes del Patía, tributario del Pacífico. Como punto de referencia, tómase el volcán de Galeras, cercano de 
la ciudad de Pasto. La mole del volcán, de 4.600 metros de altura, hállase aproximadamente a $1^{\circ} 13^{\prime} 16^{\prime \prime}$ de latitud norte, y $3^{\circ} 12^{\prime} 11^{\prime \prime} \mathrm{W}$. con relación a Bogotá. $77^{\circ} 17^{\prime} 03^{\prime \prime}$ al Oeste de Greenwich.

Por estar allí la raíz de las tres cordilleras colombianas la topografía es de una terrible y excepcional grandiosidad. Los ríos, ordinariamente sin playas, corren en hondísimos cañones aprisionados por murallas en ángulo agudo, cuyos lados se abren y elevan desde alturas de 800 metros hasta el nivel de las nieves perpetuas. La tierra es extraordinariamente fértil. La eapa vegetal aún en los sitios escarpados es de metros de espesor. Los cultivos de todos los climas colombianos prosperan con feracidad incomparable. Casi toda la tierra accesible está cultivada.

El régimen de lluvias en Nariño es en general abundante. En Pasto caen anualmente 686 milí metros de agua, en 93 días de lluvias y la humedad relativa es de $75 \%$, pero en clima templado 1.000 a 2.000 metros de elevación y $17^{\circ} \mathrm{C}$. a $22^{\circ}$ de tempo. ratura, que es precisamente la comarca azotada, la lluvia es muchísimo mayor, llegando hasta 3 metros anuales en más de 200 días de lluvia. De Potosí en Nariño, a $0^{\circ} 48^{\prime} 45^{\prime \prime}$ de latitud, que es el pueblo más austral de los atacados, hasta el Bordo en el Cauca a $2^{\circ} 06^{\prime} 52^{\prime \prime}$ de latitud norte, la Verruga afecta una extensa zona de territorio poblado por cerca de 200.000 habitantes. Según las estadísticas de la Oficina Demográfica Nacional, han muerto por Bartoneliasis 1.937 personas durante $1939 \mathrm{y}$ 1940 en 35 municipios, conforme el cuadro $N^{0} 1$.

En 1941, según estadística de la Contraloría Nacional, hubo 92 defunciones por Bartoneliasis con certificado médico, en 7 municipios y 554 designadas como Bartoneliasis, Epidemia, Peste, sin certificado médico, en 34 municipios de Nariño.

Nota demográfica. - En general, el habitante rural de esta comarca es como la mayoría del colombiano, mestizo-blanco injerto de español sobre el tronco de las viejas razas aborígenes. Pero tiene características singularmente valiosas de cultura, sobriedad y resistencia para el trabajo. El labrantío de las tierras y la manufactura de sombreros jipas o panamás, es la ocupación ordinaria de las gentes. A pesar de las cualidades ubérrimas de la tierra y laboriosidad del pueblo, se vive, singularmente en los campos, en pésimas condiciones sanitarias $\mathbf{y}$ el hombre se viste $\mathrm{y}$ se alimenta deficientemente. Los ectoparásitos son abundantes. Los salarios registran el nivel más bajo del país y el consumo de alcohol el más alto.

Origen de la epidemia. - Parece haber comenzado la epidemia en los hondos cañones del noroeste y suroeste del volcán Doña Juana, en vertientes del río Mayo y del Juanacatú, y en los tributarios del Sapuyes en el Valle de Capulí.

Los vecinos raizales la achacan a los terremotos, a erupciones del volcán Doña Juana, a deslizamien-

\section{CUADRO No}

Mortalidad por BARTONELIASIS en municipios del Departamento de Nariño en los años 1939 y 1940.

Datos de la Oficina Demográfica Nacional.

\begin{tabular}{|c|c|c|c|}
\hline MUNICIPIOS & 1939 & 1940 & TOTALES \\
\hline Pasto $\ldots . . \ldots \ldots \ldots$ & 1 & 2 & 3 \\
\hline Ancuya ............ & 17 & 3 & 20 \\
\hline Arboleda ......... & 1 & 5 & 6 \\
\hline Albán ............ & - & 9 & 9 \\
\hline Colón ........... & 11 & 5 & 16 \\
\hline Consacá .......... & 249 & 1 & 250 \\
\hline Cumbal......... & 1 & 一 & 1 \\
\hline Córdoba .......... & 67 & - & 67 \\
\hline Cuaspud .......... & 3 & - & 3 \\
\hline El Rosario ........ & 10 & - & 10 \\
\hline El Tablón ......... & 1 & - & 1 \\
\hline El Tambo ......... & - & 8 & 8 \\
\hline Funes ........... & 27 & 一 & 27 \\
\hline Cuaitarilla ....... & 80 & - & 80 \\
\hline Iles ............. & 15 & - & 15 \\
\hline Imues ............ & 23 & - & 23 \\
\hline La Cruz ........... & 3 & - & 3 \\
\hline La Florida ........ & 4 & 一 & 4 \\
\hline La Unión ......... & 131 & 38 & 169 \\
\hline Linares ........... & 49 & 141 & 190 \\
\hline Los Andes ........ & 5 & - & 5 \\
\hline Ospina $\ldots \ldots \ldots \ldots$ & 5 & 一 & 5 \\
\hline Potosí ............ & 2 & 一 & 2 \\
\hline Pupiales .......... & 3 & - & 3 \\
\hline Roberto Payán .... & 一 & 9 & 9 \\
\hline Samaniego ......... & 490 & 88 & 578 \\
\hline Sandoná....... & 149 & 87 & 236 \\
\hline San Pablo ........ & 20 & 87 & 107 \\
\hline Santacruz ........ & 27 & 一 & 27 \\
\hline Sapuyes .......... & 1 & - & 1 \\
\hline San Lorenzo ...... & 一 & 6 & 6 \\
\hline Taminango ........ & 10 & 一 & 10 \\
\hline Tangua $\ldots . . . .$. & 14 & - & 14 \\
\hline Túquerres ......... & 26 & - & 26 \\
\hline Yacuanquer ........ & 3 & - & 3 \\
\hline TOTALES.... & 1.448 & 489 & 1.937 \\
\hline
\end{tabular}

tos de La Chorrera y a grandes avenidas del río Sapuyes, cataclismos acaecidos en 1935 y 1936.

Morbilidad y mortalidad. - Desde su comienzo, ha tenido carácter invasor con inusitada virulencia y elevada mortalidad. En Capulí hay viviendas donde murieron todos los habitantes. Pueblos con promedio de 8 defunciones mensuales han registrado 64 muertos en un mes. La mayor morbilidad es en labriegos adultos, pero no respeta sexo, edad ni condición. Es rural pero invade la zona urbana. Datos muy aproximados indican que sólo en 1938 , de enero a septiembre, murieron por la enfermedad 1.800 personas. $\mathrm{Y}$ en total, pueden calcularse las víctimas en más de 6.000 . El cuadro número 2 muestra cómo en 1938 murieron v. g. en Ancuya 446 personas, para una población de 6.846 , es decir, más de $61 / 2 \%$ de los habitantes del municipio. 
CUADRO $\mathrm{N}^{\circ} 2$

Datos de la Oficina Demográfica Nacional.

\begin{tabular}{|c|c|c|c|c|c|}
\hline MUNICIPIOS & $\begin{array}{c}\text { Censo de población } \\
1938\end{array}$ & $\begin{array}{c}\text { Altura sobre el } \\
\text { nivel del mar. } \\
\text { Mts. }\end{array}$ & $\begin{array}{c}\text { Temperatura } \\
\text { grados centi- } \\
\text { grados }\end{array}$ & $\begin{array}{c}\text { Defunciones } \\
1938\end{array}$ & $\begin{array}{c}\text { Coeficiente } \\
\text { mortalidad } \\
1938 \%\end{array}$ \\
\hline Pasto .................. & 49.644 & 2.534 & 16 & 1.121 & 22,6 \\
\hline Albán...$\ldots \ldots \ldots \ldots \ldots$ & 8.415 & 1.800 & 19 & 255 & 30,3 \\
\hline Aldana $. . . \ldots \ldots \ldots \ldots . . .$. & 2.710 & 2.980 & 12 & 59 & 21,8 \\
\hline Ancuya...$\ldots \ldots \ldots \ldots$ & 6.844 & 1.302 & 22 & 446 & 65,1 \\
\hline Arboleda .............. & 8.444 & 2.170 & 17 & 204 & 24,3 \\
\hline Barbacoas ............... & 17.575 & 28 & 27 & 186 & 10,7 \\
\hline Buesaco...$\ldots \ldots \ldots \ldots$ & 9.346 & 1.935 & 19 & 225 & 12,8 \\
\hline Colón ................ & 6.859 & 1.914 & 19 & 264 & 38,4 \\
\hline Consacáa ............... & 5.667 & 1.615 & 21 & 370 & 65,4 \\
\hline Contadero ............... & 4.145 & 2.530 & 16 & 64 & 15,4 \\
\hline Córdoba ................. & 7.543 & 2.867 & 13 & 163. & 21,4 \\
\hline Cuaspud $\ldots \ldots \ldots \ldots \ldots \ldots$ & 4.038 & 3.050 & 11 & 84 & 20,8 \\
\hline Cumbal ................ & 10.418 & 3.032 & 11 & 198 & 19,0 \\
\hline El Rosario ............... & 8.143 & 500 & 24 & 80 & 9,7 \\
\hline El Tablón .............. & 4.896 & 1.619 & 21 & 185 & 36,8 \\
\hline El Tambo .................. & 12.872 & 2.193 & 17 & 180 & 14,0 \\
\hline Funes $\ldots \ldots \ldots \ldots \ldots \ldots$ & 6.988 & 2.340 & 16 & 204 & 29,2 \\
\hline Guachucal .............. & 7.708 & 3.116 & 11 & 162 & 21,0 \\
\hline Gualmatán ............... & 3.124 & 2.830 & 13 & 53 & 16,9 \\
\hline Guaitarilla $\ldots \ldots \ldots \ldots \ldots$ & 9.050 & 2.600 & 15 & 360 & 39,7 \\
\hline Iles $\ldots \ldots \ldots \ldots \ldots \ldots \ldots$ & 3.666 & 2.930 & 12 & 141 & 38,4 \\
\hline Imues $\ldots \ldots \ldots \ldots \ldots \ldots$ & 4.411 & 2.620 & 15 & 183 & 41,3 \\
\hline Ipiales $\ldots \ldots \ldots \ldots \ldots \ldots$ & 24.534 & 2.890 & 13 & 396 & 16,1 \\
\hline Iscuandé ................. & 12.478 & 5 & 27 & 157 & 12,4 \\
\hline La Cruz $\ldots \ldots \ldots \ldots \ldots \ldots$ & 14.495 & 2.484 & 15 & 249 & 17,4 \\
\hline La Florida $\ldots \ldots \ldots \ldots \ldots$ & 6.991 & 2.175 & 17 & 100 & 14,2 \\
\hline La Unión ................. & 14.018 & 1.690 & 20 & 408 & 29,1 \\
\hline Linares ................. & 7.986 & 1.200 & 22 & 132 & 16,5 \\
\hline Los Andes $\ldots \ldots \ldots \ldots \ldots$ & 11.469 & 1.588 & 21 & 101 & 8,8 \\
\hline Mallama ................ & 3.652 & 1.850 & 19 & 64 & 18,9 \\
\hline Mosquera ................ & 4.957 & 20 & 27 & 63 & 12,6 \\
\hline Ospina $\ldots \ldots \ldots \ldots \ldots \ldots$ & 3.640 & 3.000 & 12 & 128 & 35,2 \\
\hline 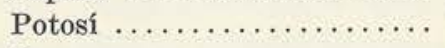 & 7.144 & 2.779 & 13 & 117 & 16,3 \\
\hline Puerres .................. & 5.466 & 2.840 & 13 & 147 & 26,5 \\
\hline Pupiales...$\ldots \ldots \ldots \ldots$ & 8.643 & 3.050 & 12 & 150 & 17,3 \\
\hline Ricaurte $\ldots \ldots \ldots \ldots \ldots \ldots$ & 4.539 & 1.240 & 22 & 59 & 13,0 \\
\hline Roberto Payán (Magüí) .... & 6.179 & 28 & 27 & 98 & 15,6 \\
\hline Samaniego ............... & 13.177 & 1.510 & 21 & 273 & 21,2 \\
\hline Sandoná $. . . \ldots \ldots \ldots \ldots . . .$. & 12.513 & 1.800 & 20 & 380 & 30,9 \\
\hline 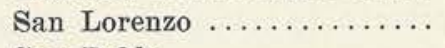 & 8.845 & 2.030 & 17 . & 82 & 9,2 \\
\hline 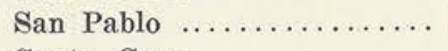 & 6.435 & 1.720 & 20 & 164 & 25,5 \\
\hline Santa Cruz $\ldots \ldots \ldots \ldots$ & 5.426 & 2.606 & 15 & 62 & 11,8 \\
\hline Sapuyes $\ldots \ldots \ldots \ldots \ldots \ldots$ & 4.029 & 3.027 & 12 & 84 & 20,8 \\
\hline Taminango $\ldots \ldots \ldots \ldots \ldots$ & 5.645 & 934 & 23 & 98 & 17,5 \\
\hline Tangua $\ldots \ldots \ldots \ldots \ldots . . . .$. & 6.714 & 2.420 & 16 & 170 & 25,3 \\
\hline Tumaco $\ldots \ldots \ldots \ldots \ldots . . . .$. & 35.082 & 5 & 27 & 477 & 3,5 \\
\hline Túquerres ............... & 20.235 & 3.104 & 11 & 433 & 21,2 \\
\hline Yacuanquer .............. & 5.010 & 2.710 & 14 & 152 & 30,3 \\
\hline TOTALES...... & 465.868 & & & 9.986 & 21,4 \\
\hline
\end{tabular}


Otálora copiló datos estadísticos todavía más tétricos (10) y finalmente comparando en tres de los municipios afectados los datos de población, natalidad y mortalidad, se puede formar el cuadro $\mathrm{N}^{\circ} 3$ que señala con números la gravedad del problema.

CUADRO $\mathrm{N}^{\circ} 3$

Mortalidad y natalidad comparativas.

\begin{tabular}{|c|c|c|c|c|}
\hline MUNiciplos & $\begin{array}{c}\text { Número de } \\
\text { habitantes }\end{array}$ & Natalidad & Mortalidad & $\begin{array}{c}\text { Coeficiente } \\
\text { de } \\
\text { mortalidad } \\
\text { por mil. }\end{array}$ \\
\hline Ancuya ... & 6.844 & 233 & 446 & 65,1 \\
Consacá ... & 5.667 & 162 & 370 & 65,4 \\
Sandoná ... & 12.513 & 488 & 380 & 30,9 \\
\hline
\end{tabular}

Sintomatología. - Hago una breve síntesis de lo observado personalmente, de informaciones verbales y publicaciones recientes (11-12-13). Sintomas dominantes en el período de invasión, etapa aguda, hemática generalizada o septicémica del mal: algias intensas, cefalalgia, raquialgia, artralgias, etc., anemia, adinamia, taquicardia, disnea, angustia precordial, anorexia, sed, fiebre irregular, remitente, ordinariamente baja, hipotensión y adenitis. Síntomas frecuentes: hiperestesia, sudores, epistaxis y otras hemorragias; erupción con puntilleo hemorrágico, petequias, máculas, constipación y albuminuria. Síntomas menos frecuentes: tos, vómitos, fenómenos oculares, sordera y estupor. A veces hay diarrea, meteorismo, sensibilidad abdominal y subictericia. La lengua irregularmente saburrosa, de bordes rojos, suele tener puntilleo y manchas oscuras (11) casi negras. De ordinario la muerte es precedida por delirio. Ortega (14) relata casos con sintomatología cerebro-espinal y Groot (15) insiste sobre la adenitis.

Resumiendo: algias, anemia, adenitis $\mathrm{y}$ fiebre irregular y anárquica, son los síntomas característicos de este período.

Ilustro este artículo con una historia calificada como la historia clínica más heroica de todos los tiempos, escrita hace 56 años de puño y letra de Daniel A. Carrión mientras tuvo fuerzas, o dictada a sus compañeros (16-5) hasta que se apagó su voz:

"Agosto 27 de 1885. A las 10 a. m. obtuve con gran dificultad que el doctor Evaristo M. Châvez ante el doctor Villar; el interno Julián Arce y el externo Sebastián Rodríguez me practicaran cuatro inoculaciones, dos en cada brazo, cerca del sitio en que se hace la vacunación, con sangre inmediatamente extraída por desgarradura de un tumor verrucoso de color rojo situado en la región superciliar derecha de Carmen Paredes, de 14 años, cama $N^{\circ}$ 5, Sala Nuestra Señora de las Mercedes, servicio del Profesor Villar, Hospital Dos de Mayo de Lima. La molestia local consecutiva a la inoculación desaparece a las dos horas siguientes". Hasta 16 de septiembre, todo normal.

"Septiembre 17. Ligero malestar y dolor en la articulación tibio tarsiana izquierda: Queda fijado el periodo de incubación: 21 días.
"Septiembre 19. El malestar se acentúa. Calofríos. Fiebre elevada $39.8^{\circ} \mathrm{C}$. Dolores generalizados. Gran postración. Tinte ictérico. Escasas petequias en la cara, alas de la nariz y frente. Calambres. Sudores. Insomnio.

"Septiembre 20-25. Todos los sintomas se agravan $\mathrm{y}$ la adinamia se acentúa.

"Septiembre 26. Noveno dia de enfermedad. Subfebril. A partir de hoy me observarán mis compañeros, pues, por mi parte, confieso me sería muy difícil hacerlo".

Los compañeros anotan ese día: palidez conside. rable de piel y mucosas. Sentimiento de debilidad general. Quebrantamiento. Inapetencia. Facultades intelectuales en perfecto estado. Pulso blando y frecuente $(100$ p.). Respiración normal. Soplo suave $y$ ligero en la base del corazón en el primer tiempo.

"Septiembre 27, $10^{\circ}$ día de enfermedad. Continúan acentuándose los síntomas de los días anteriores, a excepción de los dolores y calambres. Las manchitas de la cara van desapareciendo. Piel subictérica y aspecto terroso. Agitación e intranquilidad. La luz y el sonido le molestan. El doctor Ricardo Flórez examina la sangre y encuentra apenas 1.085 .000 glóbulos rojos. (Fue el primer recuento globular hecho en el Perú).

"Octubre 1". Náuseas. Vértigos.

"Octubre 2, $15^{\circ}$ día de enfermedad. Rostro desencajado. Ojos hundidos rodeados de un círculo negruzco. Mejillas y sienes deprimidas. Nariz afilada. Pabellones auriculares casi transparentes. Mirada sombría y velada. Voz apagada. Momentáneamente se reanima y dicta: "Me encuentro firmemente persuadido de que estoy atacado de la fiebre de la Oroya de que murí nuestro amigo Orihuela: he aquí la prueba palpable de que la fie. bre de la Oroya y la Verruga reconocen el mismo origen, como le oi decir al doctor Alarco".

"Octubre 3. El estado del enfermo es desesperado. Alucinaciones táctiles.

"Octubre 4, $16^{\circ}$ día de enfermedad. En estado gravísimo se traslada el enfermo a la casa de salud con propósito de practicarle una trasfusión de sangre. Al sacarlo de su cuarto de estudiante le dice a Izaguirre un muchacho de primer año de la escuela: "Ahora les toca a ustedes terminar la obra ya comenzada, siguiendo el camino que les he trazado". Luego cae en postración con delirio musitante en que se percibe que divaga sobre la histología de la verruga.

"Octubre 5, $17^{\circ}$ día. Carrión está moribundo. Hipotermia. Coma. A ratos emite leves quejidos y palabras incomprensibles. Hacia la alta noche, con grande esfuerzo mira a sus compañeros que solícitamente circundan su lecho, y dice: "Enrique, esto se acabó". La última expiración fue breve y profunda. A las 11 y 50 minutos de la noche Carrión estaba muerto". 
Esta historia enseña que el período de incubación de la Bartoneliasis experimental, es de 21 días. Que las algias son síntomas característicos. La fiebre inicialmente elevada, pero la muerte ocurre en hipotermia. La anemia es intensa y determina por la progresiva destrucción de glóbulos, tinte subictérico y fenómenos de angustia. Se aprecia por las petequias la lucha del organismo por localizar el virus en el sistema retículo endotelial, esfuerzo que al vencer, determina la erupción de Verrugas, triunfo de las defensas orgánicas. Se ve cómo la Verruga es inoculable al hombre y que si se inyecta sangre de verrucoma, se produce la fiebre anemizante mortal cuando las condiciones fisiológicas del paciente son propicias. $\mathrm{Y}$ se aprende que la fiebre y la Verruga tienen igual causa y apenas son dos fases de un mismo proceso.

Periodo verrucomatoso o fase histioide. - El período febril pre-eruptivo puede durar desde unos pocos días hasta varios meses y la erupción no presentarse $o$ ser tan discreta que no se advierta. La observación de los pacientes colombianos coincide casi en todo con las descripciones de los clásicos peruanos, como Odrizola, Monge, Escomel, Weiss, Rebagliati.

Trataré de hacer un fiel sumario: La erupción ordinariamente estalla días, semanas o meses después de la fiebre, al iniciarse la mejoría o más raramente durante la fase aguda. Aparece en la piel y el tejido celular subcutáneo, pero también y más raramente en las mucosas, serosas, periostio, aponeurosis, músculos u órganos internos y en general en todo tejido derivado del mesenquima. Ya se dijo que la erupción es la resultante del esfuerzo del retículo endotelio por encarcelar el virus y destruírlo. La localización, la intensidad, el número de elementos, su forma, color, aspecto y duración, son de indefinida variabilidad. En la piel iníciase principalmente en las partes descubiertas por manchitas petequiales o pequeñas pápulas blanquecinas que al desarrollarse determinan tres tipos genéricos de verrugas: miliares hasta de 3 milimetros de diámetro; nodulares hasta de 3 centímetros y tumorales (mulares porque en el Perú hay en los mulos una lesión semejante), verdaderos tumores, tamaños como limones y naranjas, hasta de 10 centímetros de diámetro. Desarrolladas las verrugas, pueden ser solitarias o confluentes. Sésiles, pero también pediculadas a tal punto que en Nariño los campesinos las estrangulan con hilos o con cabellos para que se caigan. Su color es una gama del rojo. Su constitución angiomatosa inicial, las hace fácilmente sangrables. Casi siempre aparecen por etapas sucesivas. No hay inflamación circundante en su proceso normal. No hay síntomas generales. Se marchitan y desaparecen en semanas o meses y si no han sido tratadas pasan sin dejar huella ni señal.

Los nódulos que se desarrollan en el tejido celular subcutáneo, se aprecian mejor al tacto, redondos, limitados e indoloros, cuando no están sobre zonas sensibles. Al crecer y desarrollarse empujan, adelgazan y mortifican los tejidos y afloran. Muy desarrollados y frecuentemente ulcerados, toman aspecto de tumores. Un individuo puede exhibir una verruga solitaria o llevar encima 2.500 como un caso relatado por Benavides en su tesis de grado (17).

La localización exterior o la rara pero posible en los órganos interiores de la erupción verrucomatosa, determinará como es obvio, multiplicidad de sintomas: musculares, articulares, meningoencefálicos, urogenitales, respiratorios, gastro-intestinales, etc.

Hasta ahora no se ha comunicado en Colombia ninguna defunción por Bartoneliasis en el período verrucomatoso.

Asociaciones. - La mortalidad de la fiebre verrucosa del Guáitara ha sido determinada según mi personal observación, por la Bartonella bacilliformis. Confirma esta afirmación la experiencia de Groot y compañeros de Pasto (15), quienes estudiaron 53 pacientes, 41 con Bartonellas al examen directo de sangre, 20 de los cuales fallecieron. Todos los hemocultivos en múltiples medios, repetidos hasta en período preagónico, resultaron negativos para bacterias y sólo una vez lograron cultivar un germen Alcaligenes.

Por tanto este punto está en desacuerdo con expositores del Perú, como Ribeyro (18) y otros quienes estiman que se necesita la presencia de un paratífico para que fallezca un bartonélico. Pero allí también Odriozola (19) y Rebagliati (5) afirman la especificidad de la Bartonella, suficiente para determinar la muerte.

Las protozoasis $\mathrm{y}$ helmintiasis intestinales, son entidades endémicas que parasitan a la gran mayoría de los moradores de la comarca azotada en Colombia por la Bartoneliasis, y el paludismo en algunos valles es muy grave. Jaramillo (11) relata casos de asociación de Plasmodios y Bartonellas, en la sangre del mismo paciente. Es predominante allá también la tifoidea, las espiroquetiasis y el tifo. Podrán por tanto algunas veces coexistir estas dolencias.

Causas predisponentes. - Estimo que el pobre y bajo nivel de vida del campesino, por alimentación insuficiente y mal balanceada, vestido incompleto y pocas veces cambiado y vivienda impropia, son causas que predisponen a la Bartoneliasis. Todo esto se agravó en Nariño por catástrofes regionales y cataclismos geológicos que determinaron mayor miseria y crearon además ambiente de zozobra y de ansiedad espiritual, precisamente antes del estallido epidémico.

A aquí deseo afirmar públicamente que la bancarrota de la industria casera del sombrero jipa, es una de las causas eficientes de la miseria del campesino nariñense y que es imperativo nacional reestablecer dicha industria y hacer que vuelva a flo. recer. 
Agente etiológico. - Es una Bartonella multiforme $y$ de agrupación varia que parasita los eritrocitos de los febricitantes en período inicial y en ocasiones tan densamente, que más del $90 \%$ de los glóbulos rojos están invadidos hasta por 15 y 20 elementos. Fácilmente hállasele al comienzo de la enfermedad, tiñendo las preparaciones de sangre por los métodos de Romanowski. Luego se hace cada vez más rara, hasta desaparecer. En casos de anemia y fiebre prolongada, para revelar la Bartonella es preciso hacer hemocultivos. En período histíoide o verrucoso, es difícil hallar Bartonellas en la sangre. Pero las bíopsias de verrugas muestran la forma granulosa del parásito en el citoplas. ma de células endoteliales, con impresionante semejanza a las Rickettsias. Es germen cultivable, Es inoculable a ciertos animales de laboratorio.

Se ha aceptado que la Bartonella productora de la epidemia del Sur de Colombia, es la misma Bar. tonella bacilliformis. Rebagliati (5) la define descriptivamene, en la forma siguiente: el agente espeć́fico de la enfermedad de Carrión es un microorganismo descubierto por Alberto Barton en 1905, en enfermos de fiebre o anemia grave; encontrado por Gastiaburu y Rebagliati en 1909 en enfermos de verruga eruptiva; clasificado por Strong, Tyzzer, Brues, Sellards y Gastiaburu en 1913, bajo la denominación de Bartonella bacillaformis y cultivado por Herselles en 1927.

Cultivos. - Hasta ahora el medio de elección ha sido el de Noguchi. Los hemocultivos son fáciles porque las Bartonellas viven meses en los tubos de sangre citratada, pero los cultivos son flacos y fácilmente se empobrecen con los pases. Samper y Montoya (20), modificando el medio, lograron mejores resultados. El laboratorio de Pasto trabaja sobre el mismo tema. Pero al parecer el procedimiento lógico es la siembra en huevos fértiles.

Inoculación de animales. - El resultado de mi experiencia personal es como sigue: con monos Macacus rhesus inoculados intradérmicamente o por escarificación con cultivos, se obtienen después de 10 a 30 días, verrugas semejantes a las humanas, en la mayoría de los casos; con sangre y triturado de verrugas humanas, el resultado es incierto; con sangre humana muy parasitada, inoculada en las venas, ningún resultado. Un mono rhesus, inoculado con Phlebotomus capturados por Osorno en La Unión, junto a una vivienda rural donde murieron personas por Bartoneliasis y había varios niños con verrugas, dio resultado negativo. Tiempo después, inoculado el mismo mono con cultivo, presentó un brote de verrugas. Un mono rhesus inoculado con triturado de piojos de febricitantes y verrucomatosos de Nariño, dio resultado negativo: inoculado más tarde con cultivo de Bartonella baci. lliformis, mostró verrugas clínica e histológicamente semejantes a las humanas. En los varios monos verrucomatosos cuya sangre se examinó por mucho tiempo diariamente, no se vieron Bartone- llas. Un ejemplar de Cebus fatuellus inoculado con cultivo, presentó verrugas. Con curíes normales o explenectomizados, obtuve orquiepididimitis (fenómeno de Mooser), inoculando cultivos peritonealmente y gruesas verrugas, inoculando triturado de verruga de un mono, como puede verse en las fotografías, pero los resultados son inciertos e inconstantes. Chacures, conejos, ratas, ratones y gallinas, no dieron resultado. Las tentativas en animales se resumen en el Cuadro $\mathrm{N}^{\circ} 4$.

Samper y Montoya (20) operando con materiales colectados en La Unión, por la comisión que presidió el Profesor Brumpt, dicen: "Las inoculaciones de Bartonella bacilliformis a los monos no inmunes Macacus rhesus y Cebus apella, han dado pruebas de infección en un $100 \%$ de los casos". "El perro ordinario llamado gozque, se ha mostrado bastante susceptible; muchos desarrollaron verrugas y aún algunos murieron a consecuencia de la enfermedad". Conejos, curíes, ratas, ratones blancos, y chacures, dieron resultados negativos.

Groot y compañeros (15-15 a) de Pasto, obtuvieron en dos monos rhesus infectados en las cejas $y$ abdomenn con sangre de febricitantes, rica en bartonellas, lesiones a los 30 y 33 días, con caracteres clínicos e histológicos de verruga. En curíes vieron el fenómeno de Mooser, pero muy inconstante, inoculando peritonealmente sangre. $Y$ resultados negativos con monos nativos y con pollos, inoculando sangre, medula esternal y triturado de verrugas. Iguales resultados negativos obtuvieron inoculando Cebus olivaceus y perros con triturado de Phlebo. tomus.

Transmisores. - En Colombia es esto un interrogante. En 1939 Patiño, en sus primeras comunicaciones, sindicó a los piojos (Pediculus humanus) entre los posibles vectores de la Bartoneliasis o Fiebre verrucosa del Guáitara y anotó, que como en las Rickettsiasis, los vectores podrían ser múltiples. Pero hasta ahora nada se ha definido. En junio de 1939 en La Unión, se inoculó un mono rhesus con triturado de numerosos Phlebotomus capturados alredor de una casa rural de bartonélicos, con resultado negativo. Otro mono rhesus inoculado con piojos de pacientes febricitantes y verrucomatosos de Nariño, dio resultado negativo: reinoculados meses después con cultivo de Barto. nella presentaron verrugas. Groot, Mayoral y Martínez (15) de Pasto, inocularon por todas las vías monos Cebus y perrillos con triturado de Phlebotomus, con resultado negativo y estudiaron microscópicamente 50 Phlebotomus con igual resultado negativo.

De manera que en este capítulo, no habiendo en Colombia nada definido, se debe recurrir a lo estudiado en el Perú. En 1889 Arce (21), compañero de Carrión, sentó la hipótesis de que la verruga podría ser transmitida por un insecto picador. En 1913 el entomólogo norteamericano al servicio del estado peruano, Ch. Townsend, consideró a priori (22) las titiras de las quebradas andinas (Phlebo. 
CUADRO No 4

Resumen de experimentos con animales en busca de susceptibilidad para la Bartoneliasis humana.

\begin{tabular}{|c|c|c|c|c|}
\hline \multicolumn{3}{|c|}{ Con Hacacus rhesus } & \multicolumn{2}{|c|}{ RESULTADO DEL EXPERIMENTO } \\
\hline MATERIAL DE INOCULACION & No, rhesus usados & Via de inoculación & Positivo & Negativo \\
\hline 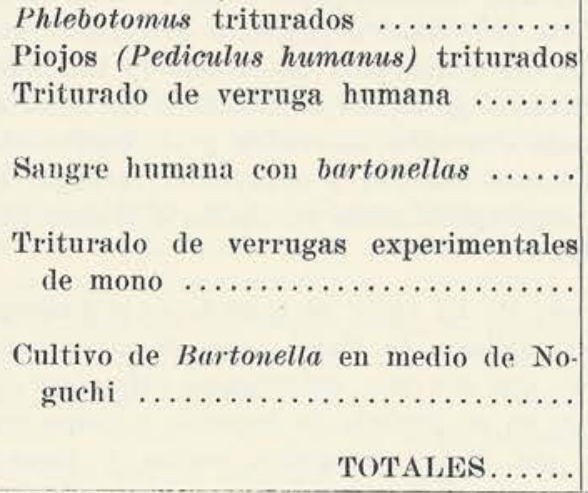 & $\begin{array}{l}1 \\
1 \\
4\end{array}$ & $\begin{array}{l}\text { Intradérmica } \\
\text { Intradérmica } \\
\text { y subcutánea } \\
\text { Intravenosa, } \\
\text { intrad. y subc. } \\
\text { Intradérmica } \\
\text { y subcutánea } \\
\text { Intradérmica } \\
\text { y subcutánea }\end{array}$ & $\begin{array}{l}\ldots \ldots \ldots \ldots \ldots \\
1 \text { por erupción } \\
\text { de verrugas } \\
6 \text { por erupción } \\
\text { de verrugas } \\
\tau\end{array}$ & $\begin{array}{l}\text { Negativo (1) } \\
\text { Negativo (2) } \\
\text { Negativos } \\
\text { Negativo } \\
1 \text { Negativo }\end{array}$ \\
\hline
\end{tabular}

(1) Probado con verrugas meses después, dio resultado positivo por ernpeión de verrugas.

(2) Probado un año después con cultivo de Bartonella presento erupción de verrugas. Sintesis: Se usaron 18 Macacus rhesus en 20 experimentos. Dos fueron probados dos veces. Dieron reacción positiva por erupción de verrugas clínica e histológicamente semejantes a las humanas $7 ; 6$ de 9 inoculados con cultíro $y 1$ de 6 inoculados con verrugas.

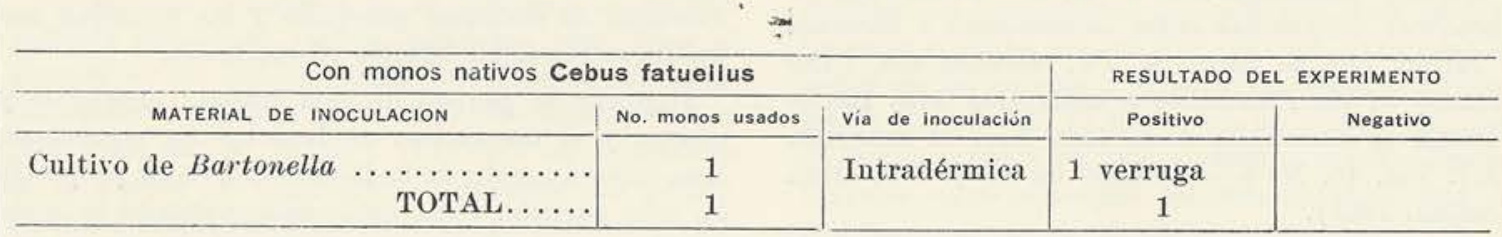

\begin{tabular}{|c|c|c|c|c|}
\hline \multicolumn{3}{|c|}{ Con CURiES normales y esplenectomizados ( 3 ) } & \multicolumn{2}{|c|}{ RESULTADO DEL EXPERIMENTO } \\
\hline MATERIAL DE INOCULACION & No. curies usados & Via de inoculación & Positivo & Negativo \\
\hline Triturado de verrugas ... & 20 normals. & Intrad. subc. & $\begin{array}{l}2 \text { por apari- } \\
\text { ción orquitis }\end{array}$ & 18 \\
\hline Sangre humana con bartonellas. & 16 & " & $\begin{array}{l}\text { 2. Uno por or- } \\
\text { quitis y } 1 \text { por } \\
\text { verr. efímeras }\end{array}$ & 14 \\
\hline Cultivos de Bartonella .......... & $\begin{array}{r}1 \\
12\end{array}$ & " & $\begin{array}{l}1 \text { orquitis } \\
2 \text { orquitis }\end{array}$ & 10 \\
\hline Emulsión de órganos ............. & 12 & " & $\ldots \ldots \ldots \ldots$ & 12 \\
\hline Triturado de piojos ............... & 5 & $"$ & $\ldots \ldots \ldots \ldots$ & 5 \\
\hline $\begin{array}{r}\text { Triturado de verrugas } \ldots \ldots \ldots \ldots \ldots \\
\text { TOTALES...... }\end{array}$ & $\begin{array}{l}3 \text { esplenect. } \\
69\end{array}$ & " & $\begin{array}{l}\text { 3. Uno orq. } \\
\text { y } 2 \text { verrugas } \\
10\end{array}$ & 59 \\
\hline
\end{tabular}

(3) Dos curfes fueron picados por Ornithodoros rudis alimentados sobre un Macacus rhesus verrucomatoso. Resultado: negativo. Sintesis: Se usaron 69 curfes, 3 de ellos esplenectomizados. Dieron resultado positivo por aparícín de verrugas 3 ; por aparición de orguitis 7 ; total, 10 positivos y 59 negativos.

\begin{tabular}{|c|c|c|c|c|}
\hline \multicolumn{3}{|c|}{ Con CONEJOS normales } & RESULTADO DE & EXPERIMENTO \\
\hline MATERIAL DE INOCULACION & No. conejos usados & Via de inoculación & Positivo & Negativo \\
\hline Triturado de verrugas & 2 & Intradérmica & $\ldots$ & Negativos \\
\hline Sangre $\ldots \ldots \ldots \ldots \ldots$ & 1 & $\begin{array}{l}\text { Intrad. e in- } \\
\text { travenosa }\end{array}$ & $\ldots \ldots \ldots \ldots$ & Negativo \\
\hline Cultivos de Bartonella & 5 & $\begin{array}{l}\text { Intrad. e in- } \\
\text { tratesticular }\end{array}$ & 1 orquitis & 4 negativos \\
\hline $\begin{array}{r}\text { Emulsión de órganos } \ldots \ldots \ldots \ldots \ldots \ldots \\
\text { TOTALES....... }\end{array}$ & $\begin{array}{l}1 \\
9\end{array}$ & Intrad. subc. & $\cdots \cdots \cdots$ & $\begin{array}{c}\text { Negativo } \\
8\end{array}$ \\
\hline
\end{tabular}

Con ratas, ratones, chacures (Dassyprocta) los resultados fueron permanentemente negativos. 
tomus) como agentes vectores del virus verrucoso, y dio a la especie el nombre de Phlebotomus verrucarum. Los estudios de Telémaco Battistini (23) y de Noguchi, Shannon, Tilden y Tyler (24), demostraron la tranmisión de la enfermedad por picadura a monos, y Battistini aisló Bartonellas del insecto. Posteriormente Herting informó hallar organismos bartoneliformes en cortes de Phlebotomus.

Noguchi y compañeros (24) publicaron que la garrapata del ganado mayor Dermacentor andersoni transmite la Bartoneliasis a los monos. Este hecho reviste para Colombia elevada importancia.

Phlebotomus de Colombia y P'erú (*). - Panamensis, squamiventris, longipalpis, evansi, osornoi, colombianus y monticolus incarum, son las siete especies catalogadas (25) en Colombia. Las dos primeras se hallaron en Restrepo, Intendencia del Meta; las tres últimas en Nariño. Las especies peruanas son tres: verrocarum, noguchii y peruensis. Es interesante notar que son distintas en los dos paises.

NOTA.-Recientemente L. E. Rozeboom dice no encontrar diferencias entre colombianus e incarum y estima que se trata de $P h$. verrucarum (The identity of the Phlebotomus associated with Bartonellosis in Colombia. Ann. Ent. Soc. of America. 1947. Vol. 40. N* 4.-Resumen de Trop. Dis. Bull. London. 1951).

Reservorios del virus. - Es otro capítulo abierto en Colombia a los investigadores. Es noción clásica que el hombre infectado de las zonas verrucosas, es reservorio de virus, ya en el estado de enfermedad o como portador crónico inaparente. Pero esto no alcanza a explicar la endemicidad. Antes que el hombre apareció en la tierra el animal, (1) y antes la planta. Y por analogía con Rickettsiasis y otros virus que tienen reservorios animales, es preciso seguir buscando. También desde su primer informe (4) dijo el autor: "Sugiero la sospecha de ser el curí reservorio de virus y aconsejo una investigación severa sobre el particular. Recomiendo igualmente investigaciones en pinglios y demás plantas lactescentes". En Nariño el curí es animal familiar, y los pinglios, Euphorbia cotinifolia y $\mathbf{E}$. latazi, forman el seto vivo que separa $1 a^{\circ}$ propiedad en algunas zonas divididas en mínimas parcelas.

Revisando literatura de pesquizas sobre reservorios, se puede destacar lo siguiente: Townsend habló de los lagartos, Tropidurus peruvianus. Pedro Weiss (26) hallo cuerpos bartoneliformes en eritrocitos de lagartijas Lacertilla $s p$. de regiones endémicas. Escomel aboga (27) porque se investigue en ratas (**) y otros roedores rurales. David Weinman y H. Pinkerton de Harvard, encontraron en el pueblo peruano de San Bartolomé, donde la verruga

(*) El primer hallazgo de Phlebotomus en Nariũo to hizo el doctor Ernesto Osorno en La Unión.

(**) El autor ha hecho investigaciones en ratas sobre Bartonella muris que se comunicarán más tarde. es endémica, curies normales portadores de Bartonellas (28).

Maldonado (29) señaló la posibilidad de que plantas euforbíaceas como huanarpos, pringamoza y otras, características de las quebradas verrrucógenas y utógenas, tuviesen papel como reservorios de virus. Weiss (30) hallo organismos bartoneliformes en el látex del huanarpo y Mackehenie y Coronado (31) cultivaron gérmenes bartonélicos de leche de euforbíaceas Jatropha macranta y $J$. baciacanta, inocularon esos cultivos y obtuvieron verrugas en gallinas, orquiepididimitis en curies e iridociclitis en conejos.

Patogenia. - El autor al comunicar el hallazgo de la Bartoneliasis de Nariño dijo en su informe inicial (4) que era una enfermedad infecciosa caracterizada en su período de invasión o etapa septicémica, por fiebre irregular, algias y anemia preponderante, que evolucionaba en días, semanas o meses, hacia una erupción verrucosa. La anemia es pues lo dominante en el período inicial y la verruga en el final. Este final se caracteriza por casi ausencia de síntomas generales y las verrugas desaparecen sin dejar huellas ni cicatrices.

Explicar la génesis de esta anemia gravísima y mortal y el mecanismo de la erupción verrucomatosa bajo la acción de la Bartonella, es mi propósito en este párrafo. Pero como está aceptada la identidad entre la Fiebre Verrucosa del Guáitara y la Enfermedad de Carrión, prefiero resumir y adaptar el inteligente capítulo patogénico de Rebagliati, formulando apenas algunos comentarios: "Inoculada por el vector, la Bartonella puede ser destruída por acción local o bien invadir el organismo por vía linfática y ganar la circulación general. Lin la sangre el germen parasita los eritrocitos reproduciéndose con mayor o menor actividad. EI período de incubación difícil de establecer en general, ha sido de 21 días para los casos experimentales. Desde el momento en que la Bartonella llega al plasma sanguíneo queda constituida la fase hemática de Weiss, (es decir, la etapa septicémica de la Fiebre verrucosa del Guáitara) revelada sobre todo por la anemia. Esta fase es muy variable en intensidad y duración, según los individuos, dependiente del estado constitucional, en especial del momento biológico en cada etapa de la infección, y quizás de la calidad (virulencia) de la Bartonella". (En la familia C., atendida en Sandoná por Jaramillo, apenas murió 1 en 10 atacados. En Yamangala, fracción de Guaitarilla, Portilla contó 80 defunciones en una población de 500 individuos). Los caracteres de la anemia han sido estudiados por Tamayo, Hercelles, Gastiaburu, Rebagliati, Monge, Mackehenie, Weiss, y últimamente por Hurtado. Groot y compañeros (15) de Pasto publicaron un resumen de sus observaciones sobre caracteres de la anemia en Nariño.

"En el mecanismo de la anemia intervienen varios factores: $1^{\circ}$ Acción parasiticida directa, porque 
la Bartonella se reproduce a expensas del eritro cito. $2^{9}$ Hemorragias y sufusiones sanguíneas en todos los tejidos con hematofagia, realizada por el sistema retículo endotelial. $3^{\circ}$ Probable toxina hemolítica de la Bartonella. La destrucción globular se hace en forma tan rápida que se puede afirmar que no existe en patologúa humana ningún otro proceso infeccioso que produzca eritropenia más rápida e intensa. Doscientos a 300.000 glóbulos rojos por milímetro cúbico pueden quedar destruídos diariamente". M. T. A., de Sandoná, primer individuo a quien se le hallaron Bartonellas en Colombia en 1939, tenía el 18 de enero 1.400 .000 eritrocitos por milímetro cúbico; 1.300 .000 el 19, y el 20 sólo 1.000.000. Jaramillo relata el caso de una niña que el 12 de abril mostró 3.600 .000 eritrocitos y el 12 de mayo 500.000. Ambos casos curaron. Menos de medio millón de eritrocitos es ya incompatible con la vida que se extingue por anemia. Si la anemia no es tan rápida e intensa hay posibilidad de que el organismo reaccione para regenerar la sangre y para organizar las defensas inmunitarias.

"Desde los comienzos de la infección el sistema retículo endotelial realiza esĩuerzos para fijar el germen en los tejidos. Estos estuerzos en los casos favorables culminan por el establecimiento de la fase histioide de Weiss". (Período verrucomatoso de la Fiebre del Guáitara). "Comienza por perturbaciones celulares degenerativas $\mathrm{y}$ exudativas, terminando en la organıación de nóbulos o verrugas donde los gérmenes quedan definitivamente fijados, constituyéndose un granuloma histiocitario, proliferación angioblástica que demuestra la reacción alérgica despertada por la noxa verrucosa, según Mackehenie y Weiss".

Histopatología (*). - Como una contribución para el capítulo de la histopatología de la Bartoneliasis colombiana, voy a transcribir extractos de los boletines de estudios hechos por encargo del autor, por M. Sánchez-Herrera, patólogo de la Facultad de Medicina, en material de autopsias humanas y biopsias practicadas en Pasto, Linares y Bogotá, y sobre verrugas experimentales obtenidas en Bogotá de Macucus rhesus y Cebus fatuellus.

Estudio de órganos humanos. $-N^{\circ}$ 1. A. D. (Varón). Material enviado por el doctor Jorge Agreda Meza. Hospital de Linares. Arboleda (Nariño). Nota clínica: Bartonellosis. Vesícula biliar. Diagnóstico histopatológico: Inflamación crónica. Edema. Muy abundantes colonias de microorganismos. Páncreas. Inflamación sub-aguda. Abundantes colo. nias de microorganismos. Estómago. Inflamación subaguda. Hay numerosas colonias de microorganismos. Riñón. Nefritis sub-aguda. Colonias de microorganismos. Bazo. Inflamación sub-aguda y crónica. Escasas colonias de microorganismos. Hígado. Hepatitis sub-aguda. Colonias de microorganismos.

(*) Aconsejo a quien quiera profundizar en la histología de la Bartoneliasis, estudiar los trabajos del sabío Profesor de Lima. Daniel Mackehenie.
Vejiga. Inflamación crónica. Én todo corte abundan colonias de microorganismos. Pulmón. Bronconeumonía sub-aguda. Escasas colonias de microorganismos. Corazón. Miocarditis sub-aguda. Colorantes usados: Hematoxilina, Eosina, Giemsa.-Febrero $1^{\circ}$ de 1940.

Sánchez-Herrera considera que los microorganis. mos hallados son Bartonellas.

$N^{\circ}$ 2. P. R. (Varón). La Magdalena (Nariño). Caso del doctor Vallecilla. Nota clínica: Siete días de hospitalización. Trece días de enfermedad. Sín. tomas: Epistaxis, ictericia, anemia, hepatomegalia. Temperatura el día de la muerte, por la maũana, $39^{\circ} \mathrm{C}$. Pulso, 120. Descripción macroscópica: Fragmentos de tejido blando recibidos en líquido fijador. Diagnóstico histopatológico: Hígado, vesícula biliar y ganglio linfático. Bartonellosis. En todos los cortes examinados, hay lesiones de estructura. En el hígado se observa degeneración grasosa moderada. En la vesícula biliar, hay infiltración leucocitaria mononuclear muy moderada. El ganglio presenta hiperplasia del tejido reticulo-endotelial e infiltración leucocitaria mononuclear muy moderada en la cápsula. En los tres órganos, pero especialmente en la vesícula y el ganglio, llama particularmente la atención la presencia de microorganismos de forma cocoide en masas intra y extra celulares, algunas veces formando cadenas hasta de seis elementos.-Agosto 22 de 1940.

$N^{o}$ 3. C. Y. (Varón). Pasto (Nariño). Caso del doctor Vallecilla. Nota clínica: Hormaciones verrucosas de los ganglios mesentéricos, halladas en la autopsia. Descripción macroscópica: Dos fragmentos de tejido blando de forma lenticular y superficie de sección lisa y uniforme. Diagnóstico histopatológico: Ganglio linfático. Adenitis sub-aguda. Bartonellosis. Al microscopio se encontró ganglio linfático afectado por un proceso inflamatorio. En la cápsula hay infiltración leucocitaria mononuclear. En el parénquima edema e hiperplasia del retículo endotelio. No son raros los eosinófilos. Se encontraron numerosas colonias de microorganismos cocoides, generalmente intracelulares.-Diciembre 3 de 1940.

$N^{\circ}$ 4. J. B. $($ Cabo 19). Caso de los doctores P. C. y S. (32) Hospital Militar. Nota clínica: De Sandoná (Nariño) venido a Bogotá a principios de abril. Hospitalizado el 18. Diagnóstico clinico y experimental: Bartoneliasis. Fallecido el 28 de mayo. Hígado. Cápsula lisa. Al corte la superficie de sección es de color amarila, casi carmelita. Diag. nóstico histopatológico: Hepatitis sub-aguda. Congestión pasiva. Degeneración grasosa. Colonias de Bartonellas. Los cortes muestran parenquima hepático afectado por un proceso inflamatorio que se caracteriza por focos de infiltración leucocitaria mononuclear, en los espacios periportales en donde además hay aumento del tejido conjuntivo fibroso. En las células hepáticas abundan globos pequeños de grasa. Hay dilatación de las venas centrales y 
edema del parenquima que las rodea. En el tejido intersticial se encontraron algunas colonias compuestas de elementos cocoides, generalmente extracelulares y agrupados en pares, líneas, etc. Bazo. Cápsula lisa. La superficie de sección es de color rojo y muestra algunas áreas morenas. Congestión y edema. No se encontraron microorganismos. Intestino delgado. Cambios post-mortem. Numerosas colonias de bartonellas. Los cortes muestran intestino delgado ya en estado de desintegración celular. En la luz llama particularmente la atención la variedad y la abundancia de microorganismos. En la capa muscular se ven numerosas masas de microorganismos, de forma cocoide, intra y extra ce. lulares. Con frecuencia algunas de estas formas se agrupan recordando un elemento bacilar. Riñón. Cápsula lisa y con algunas adherencias. Al corte la superficie de sección es de color gris pálido con algunas áreas de color gris oscuro que se extienden desile la corteza hasta la medula. La arquitectura se aprecia mal. Glomerulo-nefritis sub-aguda. Cambios post-morten. No se encontraron bartonellas. Los cortes muestran al microscopio tejido renal afectado por un proceso inflamatorio que se localiza especialmente en la región cortical. Hay infiltración lencocitaria poli y mononuclear. Se observa desintegración celular. Suprarrenal. Al corte se aprecian bien la corteza y la medula. La primera de color amarillo y la segunda de color gris pálido. Colonias de bartonellas. Cambios postmorten. Los cortes muestran al microscopio numerosas colonias de microorganismos cocoides, generalmente extra celulares y arreglados en cadenas hasta de ocho elementos. Llama particularmente la atención la presencia de numerosas formas bacilares cuya naturaleza no es fácil determinar. Las células parenquimatosas presentan cambios postmorten. Páncreas. Consistencia normal. Color amarillo pálido. Abundantes colonias de bartonellas. Cambios post-morten. Al microscopio se encuentra tejido pancreático en estado de desintegración celular. Se ven numerosas agrupaciones de formas cocoides, intra y extra celulares y arregladas en cadenas de dos o más elementos. Corazón. Se aprecian endocardio, miocardio, y pericardio. Cambios post-morten. No se encontraron microorganismos. Los cortes muestras desintegración de la fibras musculares e infiltración por líquido transparente. Pulmón. Aspecto normal. Antracosis muy moderada. Enfisema. No se enccontraron bartonellas. En los cortes se observa descamación del epitelio bronquial, antracosis moderada, células cardíacas y áreas de enfisima. Colorantes usados: Hematoxilina, Eosina, Giemsa.-Julio 10 de 1940.

Estudio de Verrugas humanas.-No 1. J. M. (Varón). Pasto (Nariño). Caso del doctor Vallecilla. Nota clínica: Verruga extirpada de la oreja de J. M. del Hospital de La Unión. Este enfermo no presentó forma febril. Descripción macroscópica: Un fragmento de tejido blando recibido en líquido fijador. Diagnóstico histopatológico: Verruga. Barto- nellosis. Se observa epitelio escamoso estratificado y tejido conjuntivo sub-epitelial. En este último hay un proceso inflamatorio sub-agudo que se caracteriza por infiltración leucocitaria mono y polinuclear. En el tejido fijo hay proliferación. En los vasos se observa hiperplasia de las diferentes capas, a veces con trombosis. Algunas células parecen ser angioblastos. Edema. Llama particularmente la atención la presencia de numerosas colonias de microorganismos de forma cocoide y nítidamente coloreados, algunas veces en cadenas hasta de siete elementos. Generalmente son extracelulares. También es interesante anotar que el microorganismo anterior algunas veces está asociado a otro. de forma bacilar, muy proliferante y que toma muy débilmente los colorantes. Colorantes usados: Hematoxilina, Eosina, Giemsa.-Diciembre 2 de 1940.

No 2. F. A. (Mujer). Pasto (Nariño). Caso del doctor Vallecilla. Nota clínica: Verruga extirpada del pabellón de la oreja. Hace un mes le comenzó la enfermedad con dolores generalizados, raquialgia, cefalea, quebrantamiento y fiebre intensa. A los 8 días, después del estado febril, comenzaron a bro. tar las verrugas. Presenta una verruga del tamaño de una núez en la parte posterior de la boca y que se inserta en la base de la lengua. Esta neo-formación, sangra mucho, dificulta la deglución y la respiración. También tiene verrugas del tamaño de garbanzos en las mejillas, orejas y barba. Descripción macroscópica: La pieza es una masa de tejido blando, regularmente esférica, recibida en líquido fijador. Diagnóstico histopatológico: Verruga. Bar. tonellosis. El material enviado para examen, muestra epitelio escamoso estratificado y tejido conjuntivo sub-epitelial. En este último se ve un proceso inflamatorio sub-agudo caracterizado por una enorme proliferación del tejido conjuntivo y por infiltración leucocitaria, con predominio de los mononucleares. En los vasos se observa hiperplasia muy marcada y algunas veces trombosis. Se encontraron colonias intracelulares de forma cocoide y nítidamente coloreadas. Los eosinófilos son particularmente abundantes. Colorantes usados: Hematoxilina, Eosina, Giemsa.-Diciembre 3 de 1940.

No 3. H. O. (Mujer). Pasto (Nariño). Caso del doctor Vallecilla. Nota clínica: Verruga extirpada a la enferma H. O. Descripción macroscópica: Un fragmento de tejido blando y de forma ovoide. Aparentemente está bien encapsulado. La superficie de sección es lisa y uniforme. Diagnóstico histopatológico: Verruga. Bartonellosis. Los cortes muestran epitelio escamoso estratificado $\mathrm{y}$ tejido conjuntivo sub-epitelial. En este último se aprecia un proceso inflamatorio que se caracteriza por edema, proliferación del tejido fijo e infiltración leucocitaria poli y mononuclear. En los vasos hay hiperplasia celular. Se encontraron algunas colonias de microorganismos cocoides, generalmente intracelulares. Colorantes usados: Hematoxilina, Eosina, Giemsa. Diciembre 3 de 1940. 
Estudio de Verrugas de Monos rhesus. - No 1. Macacus rhesus $N^{\circ}$ 12. Organo o tejido: Piel. Nota clínica: Inoculado el 18 de octubre de 1939 con cultivo de Bartonella bacilliformis. Cepa N. Reinoculado el 31 de octubre del mismo año con la misma cepa. Descripción macroscópica: Un pedazo de piel. Diagnóstico histopatológico: Inflamación aguda. No hay bartonellas. Los cortes hechos muestran piel y tejido celular subcutáneo, ambos afectados por una reacción inflamatoria. La infiltración leucocitaria es muy abundante y predominan los polinucleares. Hay formación de pús y proliferación del tejido conjuntivo. Los vasos están congestionados generalmente. Edema moderado.- Junio 15 de 1940.

No 2. Macacus rhesus $N^{o}$ 13. Organo o tejido: Piel. Nota clínica: Inoculado el 31 de octubre de 1939 con cultivo de bartonella, Cepa N. En el sitio de la inoculación presentó una verruga, la que fue extirpada el 4 de enero de 1940. Diagnóstico histopatológico: Piel. Inflamación crónica. No hay evidencia de bartonellas. Al microscopio se encuentra piel y tejido celular subcutáneo afectados por un proceso inflamatorio que se caracteriza por gran proliferación del tejido conjuntivo e infiltración leucocitaria, especialmente mononuclear. Se obser. van numerosos eosinófilos. Edema moderado.-.Junio 15 de 1940 .

$N^{9}$ S. Macacus rhesus $N^{\circ} 11$. Organo o tejido: Piel. Nota clínica: Inoculado intradérmicamente con 1/2 cc. y con 1 cc. intravenosamente con triturado en solución salina de Pediculus capiti y vestimenti de varios enfermos de Nariño, con resultado negativo. El 8 de enero de 1940 se inoculó intradérmicamente con $0.40 \mathrm{cc}$. de cultivo procedente de sangre tomada por el señor Clodomiro Rodrígnez Caycedo, laboratorista de Sandoná, a N. B., enfermo de Bartoneliasis. Las verrugas comenzaron a brotar el 14 . El $1^{\circ}$ de febrero de 1940 se le extirpó una verruga. Diagnóstico histopatológico: Los cortes muestran piel. En el epitelio hay descamación. No hay cambios de estructura. No se encontraron bartonellas. Julio 15 de 1940.

$N^{\circ}$ 4. Macacus rhesus $N^{\circ}$ 19. Organo o tejido: Piel. Nota clínica: Inoculado con hemocultivo de sangre, procedente del Cabo J. B., del Hospital Militar, el 5 de junio de 1940. Extirpación de verrugas bajo anestesia general el 25 de junio de 1940. Descripción macroscópica: Dos fragmentos de piel. Diagnóstico histopatológico: Piel. Inflamación sub-aguda. Colonia de Bartonellas. El material enviado para examen, muestra al microscopio, piel y tejido celular subcutáneo. En este último hay un proceso inflamatorio con infiltración leucocitaria poli y mononuclear, edema, pequeños focos de supuración, neoformación de vasos y proliferación del tejido conjuntivo. Llama particularmente la atención, la abundancia de células formadoras de vasos. Merecen también citarse, numerosas colonias de microorganismos cocoides intra y extracelulares. Por la manera de colorearse y por su agrupación, recuer- da.n la bartonella. Colorantes usados: Hematoxilina, Eosina, Giemsa.-Septiembre 25 de 1940.

$N^{\circ} 4$ A. Macacus thesus $N^{o} 19$. Verrugas del vientre. Organo o tejido: Piel. Nota clínica: Inoculado el 5 de junio de 1940 por vías subcutánea, intravenosa e intradérmica con $3 \frac{1}{2}$ cc. de cultivo procedente de sangre del Cabo J. B., del Hospital Militar. Se le tomó una bíopsia de la región abdominal el día $1^{\circ}$ de julio de 1940. Diagnóstico histopatológico: Inflamación sub-aguda y crónica. No se encontraron microorganismos. Piel y tejido celular subcutáneo. En este último hay una zona inflamada que se caracteriza por infiltración leucocitaria poli y mononuclear, neoformación de vasos, hiperplasia perivascular y proliferación del tejido conjuntivo fibroso. Las células endoteliales se presentan como elementos atrofiados de citoplasma abundante y presentan unas reces signos de degeneración grasosa y otras de degeneración hialina. No son raras las células eosinófilas. Tanto en el endotelio como en el tejido conjuntivo se observan frecuentemente fenómenos de picnosis, cariolisis y cariorrexis. Edema moderado. Focos pequeños de hemorragias.-Tulio 12 de 1940.

Verrugas de Monos Cebus.-Cebus No 3 ("). Or. gano o tejido: Piel. Nota clínica: Mono Cebus inoculado en la región supraciliar de ambos lados con $1 / 4$ cc. y con 1 cc. en la región abdominal intradérmicamente con cultivo 18 procedente de sangre del Cabo J. B., del Hospital Militar, el 22 de junio de 1940. El 6 de julio aparecen verrugas en la cara y abdomen. El 15 se extirpan dos verrugas supraciliares para estudios histológicos e inocular con triturado curíes, un perro y el rhesus 21. Diagnóstico histopatológico: Inflamación sub-aguda en estado regresivo. Al microscopio se encuentra piel y tejido celular subcutáneo, este último afectado por un proceso inflamatorio. Infiltración leucocitaria mono nuclear muy moderada. Se observa neoformación de vasos. Edema escaso. No hay focos de necrosis. En algumos campos se encuentran microorganismos de forma cocoidea, no fijan bien los colorantes y parece que estuvieran en estado de desintegración. No es posible identificarlos. Colorantes usados: Hematoxilina, Eosina, Giemsa.-Septiembre 19 de 1940.

Diariamente se examinó sangre hasta el 16 de septiembre, sin hallar hemoparásitos.

Amanece muerto el 22. Se hace la autopsia en la mañana del mismo día. Diagnóstico histopatológico: Canglio linfático, páncreas, corazón, glándula salivar, piel, riñón, hígado, suprarrenal, bazo, vejiga, pene y pulmón. En la piel se encontró un proceso inflamatorio localizado especialmente en la región dérmica en donde se pueden apreciar microorganismos cocoides aislados, en cadenas de dos o más elementos o formando masas. Son extra o intra-

(०) Este animal con verrugas experimentales se exhibio ante los profesores de clínica médica en el Hospital de San Jnan de Dios el 15 de julio de 1940, con ocasión de la visita del ilustre Profesor norteameriano William Sharpe. 
celulares. En el tejido conjuntivo hay proliferación y se observa hiperplasia e hipertrofia en las paredes de los vasos sanguíneos. La infiltración leucocitaria es muy escasa. En la superficie de la piel se observan descamación y se aprecian colonias de microorganismos. Algunos glóbulos rojos parecen parasitados por los microorganismos que se acaban de describir. Los demás órganos examinados no muestran alteraciones.-Octubre 23 de 1940.

Diagnóstico diferencial. Fase septicémica o hemática.-El diagnóstico clínico de la Bartoneliasis en su fase septicémica o hematica es difícil porqüe se asemeja a muchas dolencias agudas. Así se explica que en Nariño pasara la epidemia tanto tiempo indeterminada $\mathrm{y}$ que fuera un largo divagar el proceso anterior al diagnóstico. Como paludismo, tifoidea y gripa fue calificada de 1936 a 1939 . Pero también se parece al tifo y sus congéneres, a la fiebre amarilla, a las espiroquetiasis, al dengue, a la fiebre ondulante. La anemia intensa y ascendente, la taquicardia, las algias, la fiebre irregular de tipo anárquico, la hipertrofia ganglionar, son signos clínicos y síntomas que ayudan al diagnóstico diferencial. La noción geografica es argumento de gran probabilidad. Y el criterio de certeza lo da el hallazgo de las Bartonellas en la sangre.

Fase histioide o verrucomatosa.-En su fase histioide o verrucomatosa paś la Bartoneliasis de Nariño por Pian, antes de 1939. Aunque puede también confundírsele con otras lesiones de la piel, estimo que en Colombia debe subrayarse el diag. nóstico diferencial con el Pian, otra grave plaga endémica de los Andes Colombianos, singularmente de las vertientes pacíficas del Chocó, porque ahí también hay propicio ambiente para la Verruga.

Con algunas variaciones transcribo en gran parte la clave de Escomel citada por Maldonado (33) para el diagnóstico diferencial entre el Pian y la Verruga:

CLAVE PARA EL DIAGNOSTICO DIFERENCIAL ENTRE LA VERRUGA PERUANA Y EL PIAN, REDACTADA POR ESCOMEL (34)

\begin{tabular}{|c|c|c|}
\hline Caracteres. & Pian. & Verruga. \\
\hline Invasión. & $\begin{array}{l}\text { Fiebre. Alteraciones digestivas. Cefa- } \\
\text { lea. Dolores reumatoides. }\end{array}$ & $\begin{array}{l}\text { Fiebre anárquica. Dolores reumatoi- } \\
\text { des. Postración. Anemia. Adenitis. }\end{array}$ \\
\hline Erupción. & $\begin{array}{l}\text { Máculas, descamación furufurácea de } \\
\text { la piel, hiperkeratosis palmar y plan- } \\
\text { tar. }\end{array}$ & No. \\
\hline Chancro. & $\begin{array}{l}\text { Chancro piánico, primer botón inicial. } \\
\text { Buba madre. }\end{array}$ & $\begin{array}{l}\text { No hay manifestación eruptiva inicial- } \\
\text { mente. }\end{array}$ \\
\hline $\begin{array}{l}\text { Erupción } \\
\text { invasión. }\end{array}$ & $\begin{array}{l}\text { Recrudescencia febril con generaliza- } \\
\text { ción de los pianomas. }\end{array}$ & $\begin{array}{l}\text { Aparece la erupción cuando disminuye } \\
\text { o desaparece la fiebre y los sintomas } \\
\text { generales. }\end{array}$ \\
\hline $\begin{array}{l}\text { Erupeión } \\
\text { estado. }\end{array}$ & $\begin{array}{l}\text { Botones carnosos recubiertos por una } \\
\text { costra amarillenta. Bubas. }\end{array}$ & Botones eréctiles sin costra. Verrugas. \\
\hline $\begin{array}{l}\text { Erupción } \\
\text { estado. }\end{array}$ & $\begin{array}{l}\text { Color: rosa claro. Consistencia: bas- } \\
\text { tante firme. Aspecto: el de las lesio- } \\
\text { nes sifilíticas. }\end{array}$ & $\begin{array}{l}\text { Color: púrpura. Consistencia: blanda. } \\
\text { Aspecto: de los naevi superficiales } \\
\text { bien vasculares. }\end{array}$ \\
\hline Regresión. & Con lesiones de la piel circundante. & Sin lesiones de la piel circundante. \\
\hline Regresión. & Algunas veces deja cicatrices. & No deja jamás cicatrices. \\
\hline $\begin{array}{l}\text { Agente } \\
\text { causal. }\end{array}$ & Treponema pertenue (Castellani, 1905). & $\begin{array}{l}\text { Bartonella bacilliformis. } \\
\text { (Strong, 1913). }\end{array}$ \\
\hline Terapéutica. & $\begin{array}{l}\text { Específica y rápida por los arsenoben- } \\
\text { zoles y el bismuto. }\end{array}$ & $\begin{array}{l}\text { No obedece a los arsenobenzoles. Hasta } \\
\text { hoy no posee medicación específica. }\end{array}$ \\
\hline
\end{tabular}

Pronóstico. - Es reservado para la forma grave de Bartoneliasis en su fase septicémica o hemática. Es favorable en la fase verrucomatosa o histioide cuando ya el organismo ha vencido, aprisionado el germen por medio del sistema retículo endotolial y organizando la inmunidad que parece definitiva.

Tratamiento. - No se conoce todavía el remedio específico contra la Bartoneliasis. El tratamiento consistirá en hospitalización, quietud, aseo, buena alimentación y moderada medicación sintomática. De tiempo inmemorial (35) se ha preconizado en las regiones peruanas los revulsivos estimuladores del retículo endotelio: allá úsase el maguey; acá Groot (15) aconseja la mostaza; la balneoterapia caliente sería el procedimiento de elección. Küczynski (36) recomienda el sulfato de cobre. Bernales 


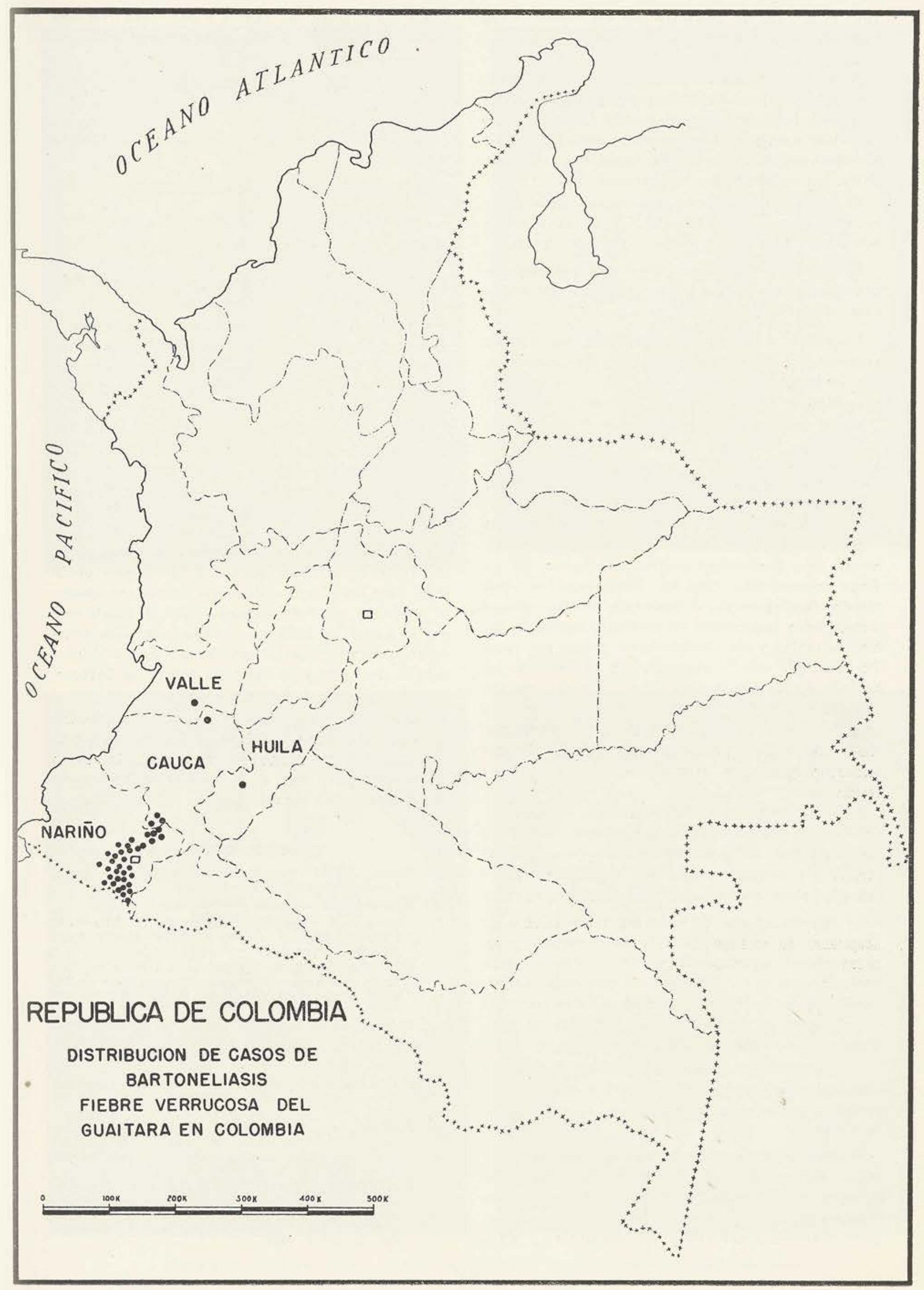



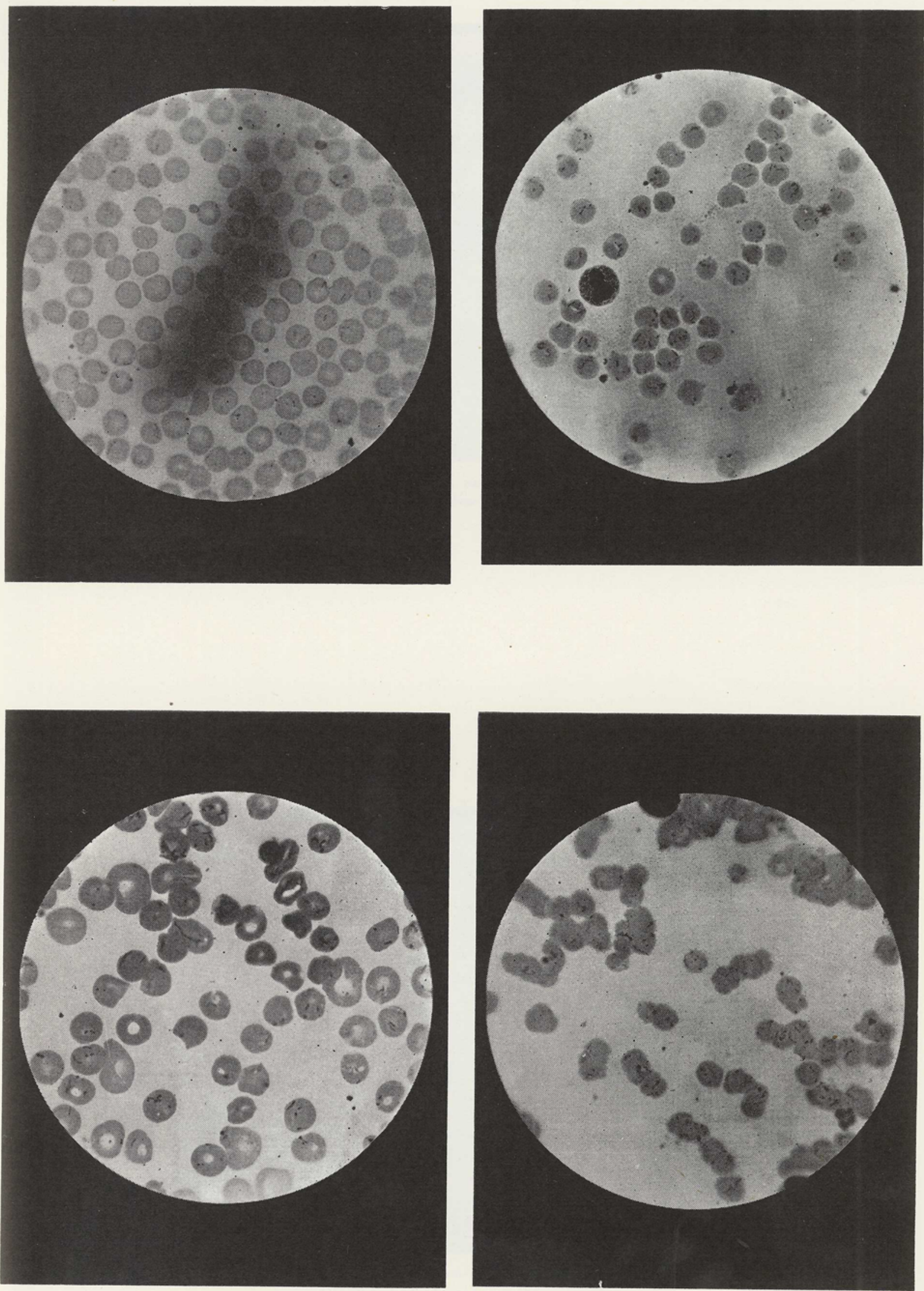

MICROFOTOGRAFIAS. Sangre parasitada con abundantes Bartonellas. Coloración: Leishman-Giemsa. 


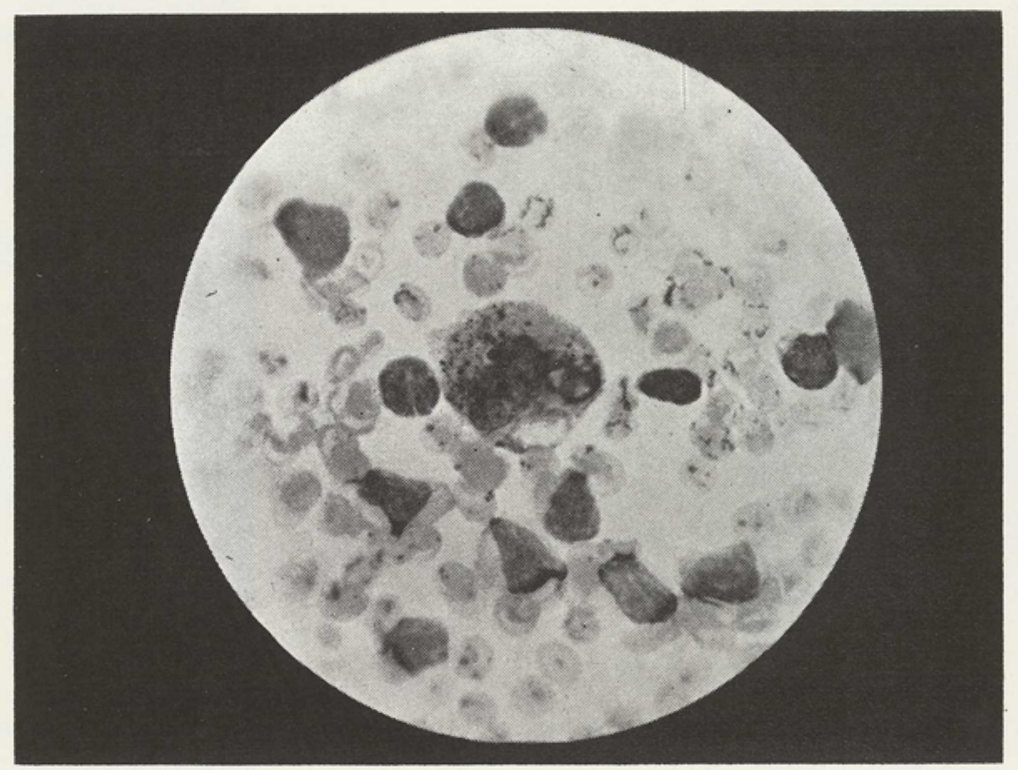

MICROFOTOGRAFIA. Célula vaginal de curí orquítico inoculado con hemocultivo humano. Granulaciones citoplásmicas.

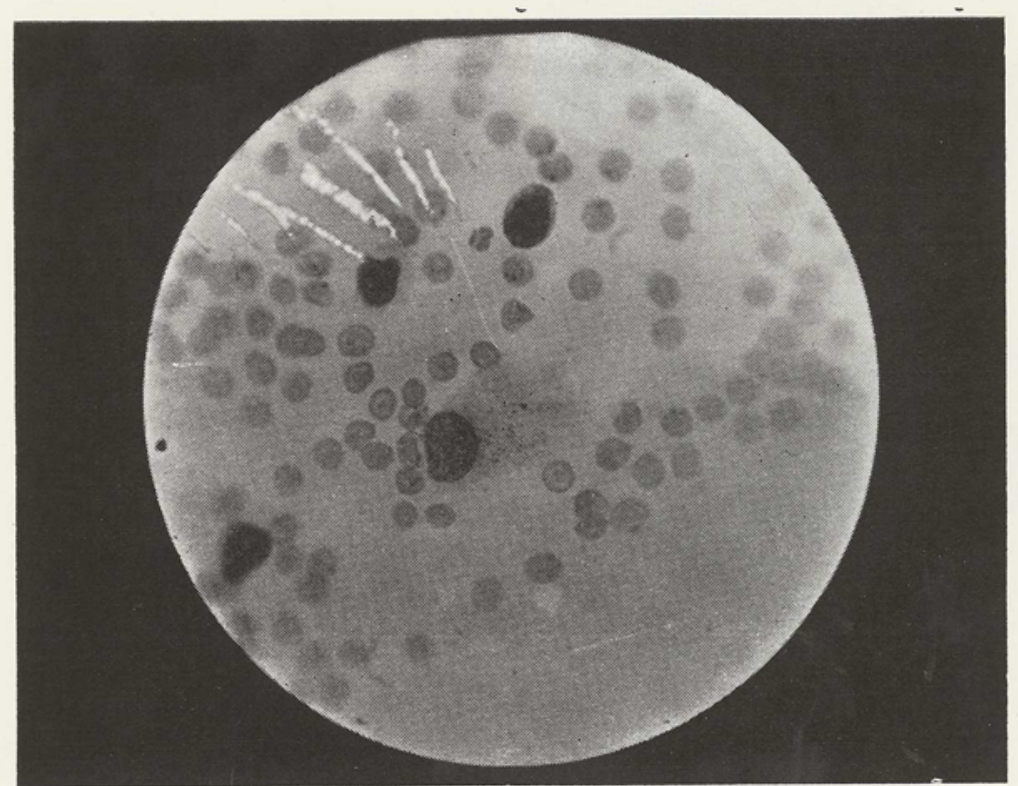

MICROFOTOGRAFIA. Impresión de verrucoma. Una célula llena de granulaciones acidófilas. Coloración: Leishman-Giemsa. 

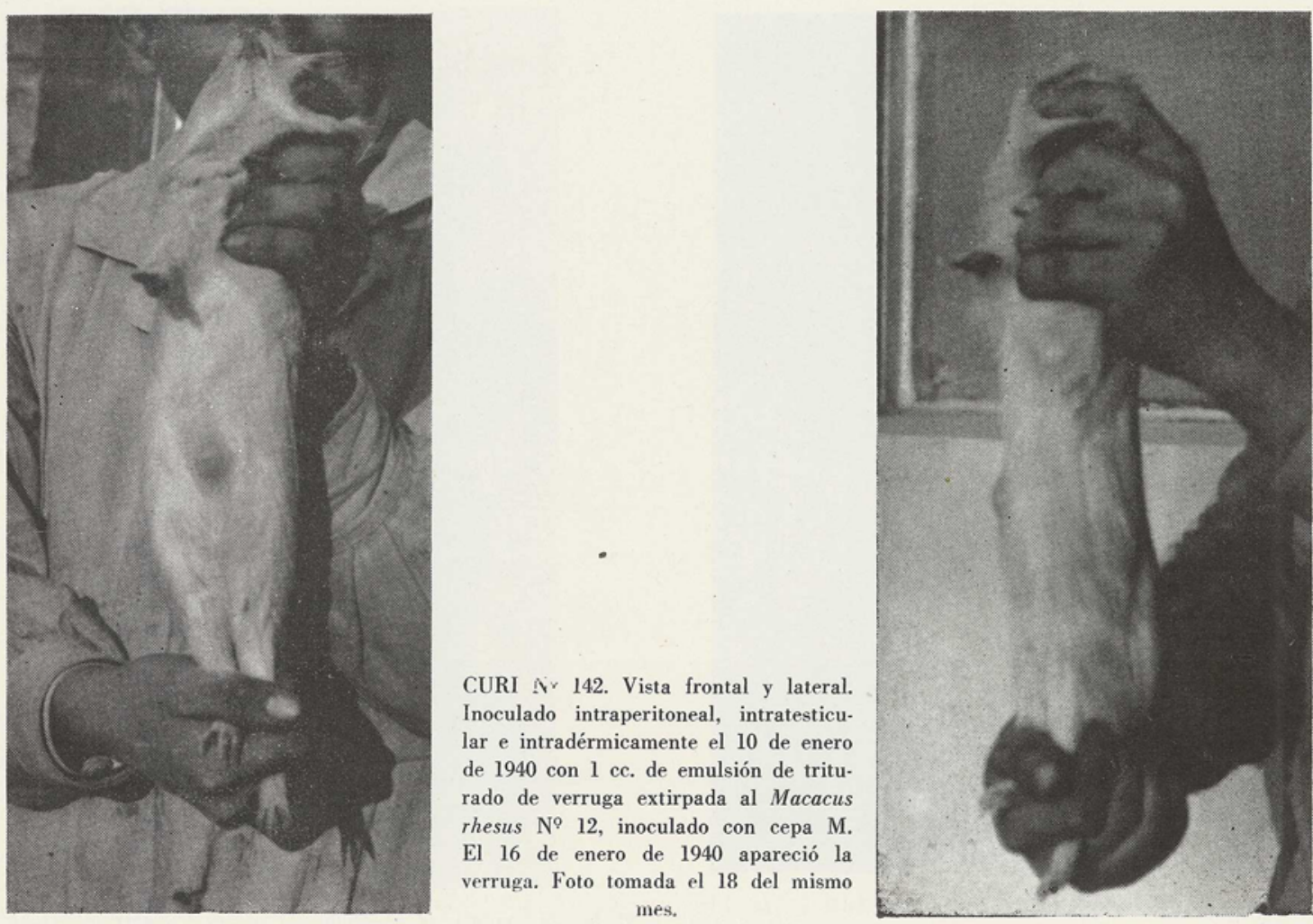

CURI $N^{9}$ 179. Esplenectomizado el 7 de marzo de 1940. Inoculado intraperitoneal e intradérmicamente el 21 de febrero de 1940 con $1 / 2$ cc. de hemocultivo de Isaac Carataca, sangrado en Samaniego a orillas del río Pacual el 14 de febrero de 1940, por el Dr. Hernando Groot, Director del Laboratorio de Pasto.

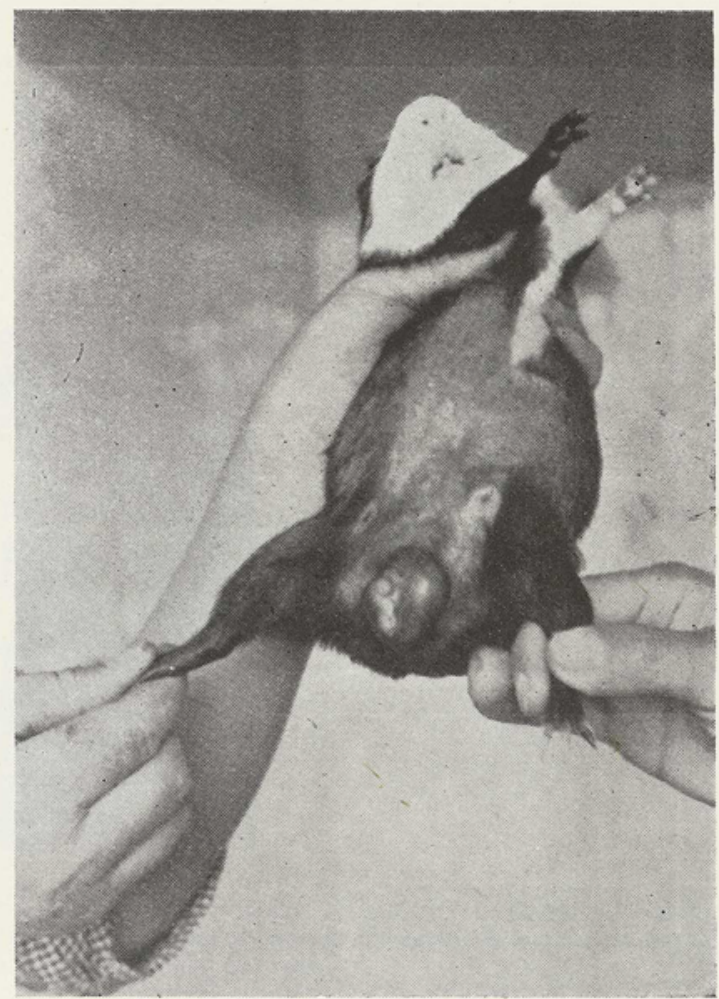




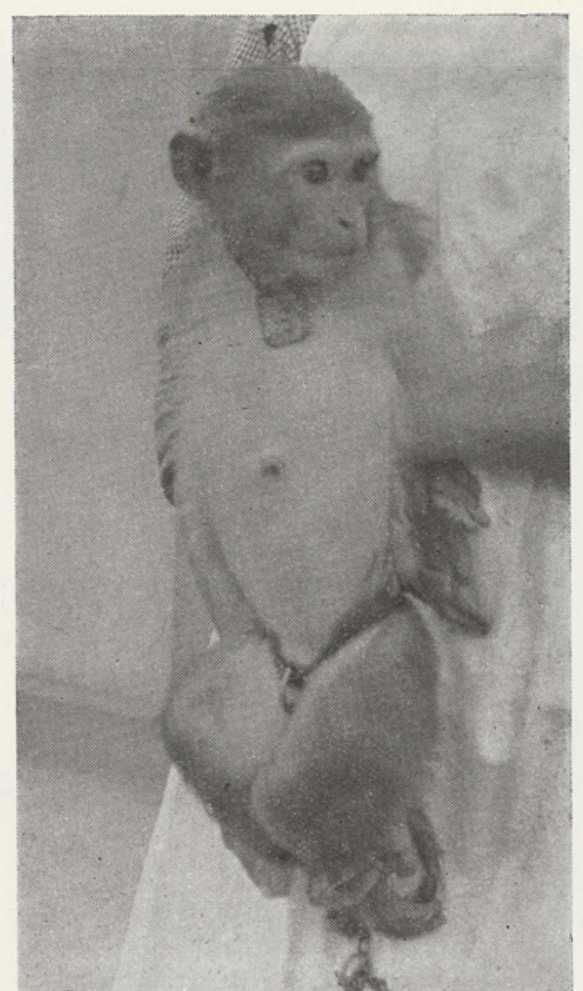

MACACUS RHESUS $\mathrm{N}^{\circ}$ 8. Inoculado en La Unión (N.) el 22 de junio de 1939 intradérmicamente en la cara con emulsión salina de triturado de 14 Phlebotomus con resultado negativo. El 4 de enero de 1940 se inocula intradérmicamente en la cara y región abdominal con $1 / 2$ cc. de emulsión en solución salina de triturado de una verruga extirpada al Macacus rhesus $\mathrm{N}^{2} 13$. El 31 de enero de 1940 apareció una verruga en la región abdo. minal. El 13 de febrero aparecen principios de verrugas en la ceja izquierda.

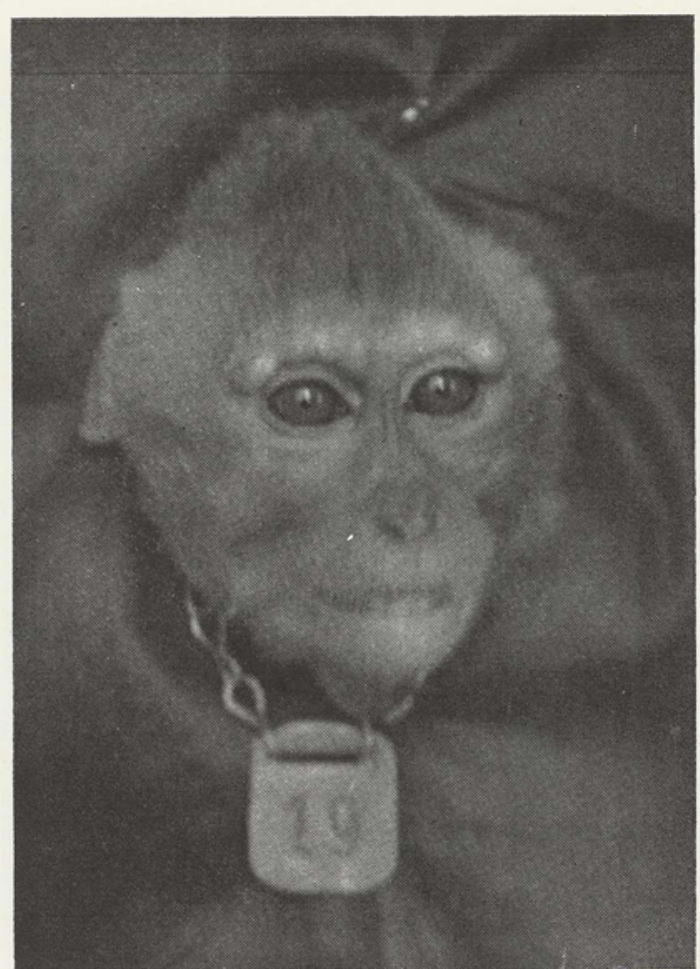

MACACUS RHESUS No 19. Inoculado el 5 de junio de 1940 con cultivo semisólido procedente de sangre del Cabo J. B. Intradérmicamente en las cejas con $1 / 2$ cc.; subcutáneamente en la región abdominal con 1 cc. e intravenosamente con 2 cc. El 20 de junio muestra 4 verrugas en la cara. El 22 se toman fotografías.

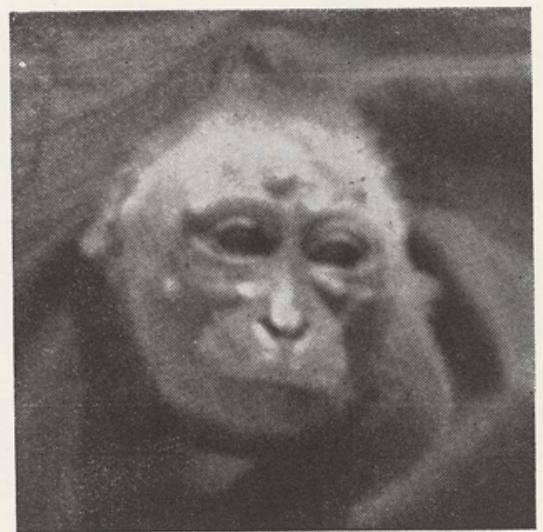

MACACUS RHESUS No 14. Inoculado intradérmicamente en las cejas y mejillas con 1 cc. de emulsión de cultivo 3 (J B Y) el 26 de enero de 1940. Foto tomada el 12 de febrero de 1940. La sangre fue tomada por don Clodomiro Rodríguez y Caycedo, laboratorista de Sandoná, el 13 de noviembre de 1939. 

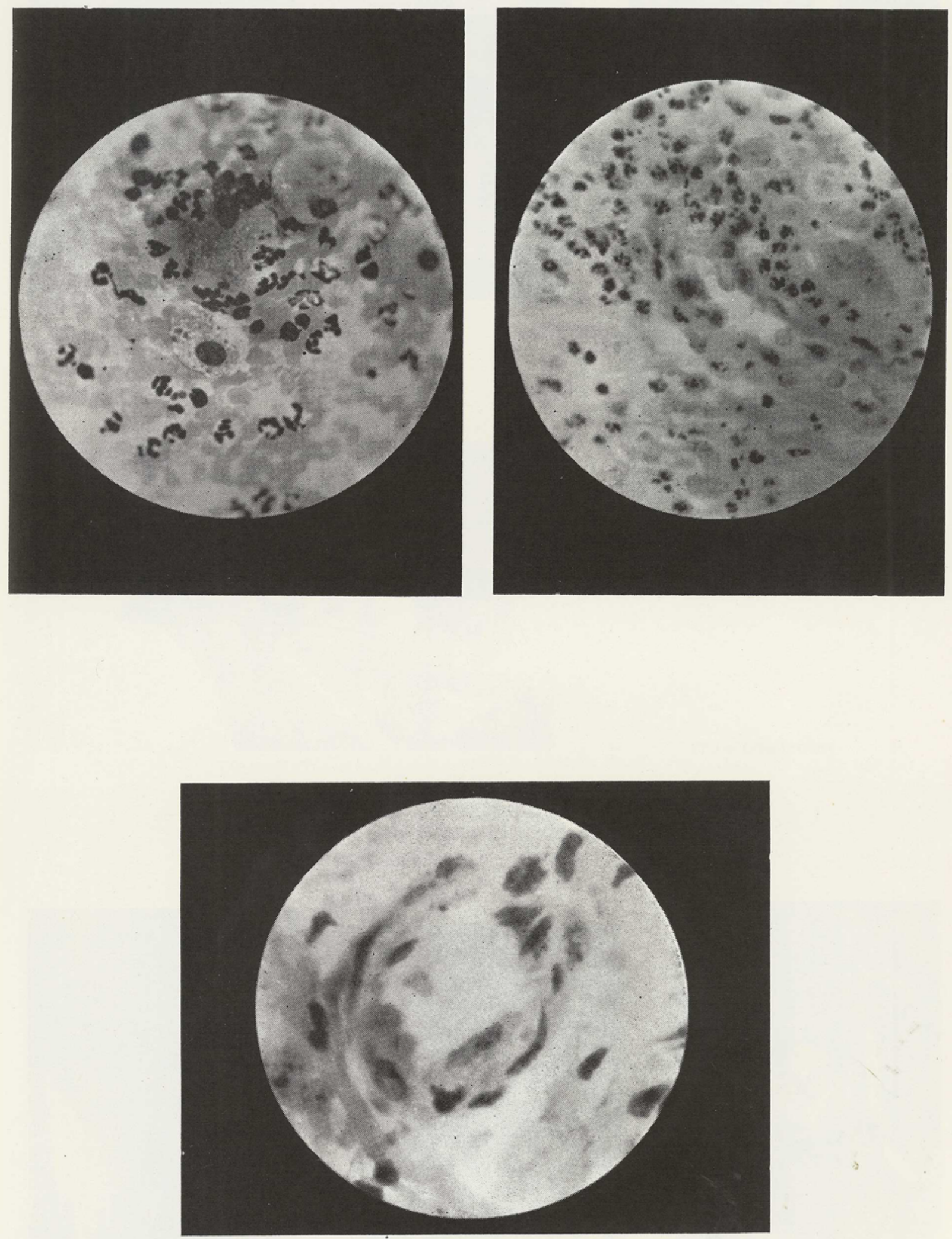

MICROFOTOGRAFIAS de cortes de verruga del Macacus rhesus $\mathrm{N}^{9} 19 . \mathrm{N}^{\circ}$ 1: verruga eiliar; coloración por May-GrunwalGeimsa; células llenas de granulaciones acidófilas: $\mathrm{N}^{0} 2$ : corte longitudinal de un capilar de neoformación; obsérvese en el tejido circundante el proceso inflamatorio. № 3: corte transiversal de un capilar de neoformación.--Dr. M. Sánchez Herrera. 

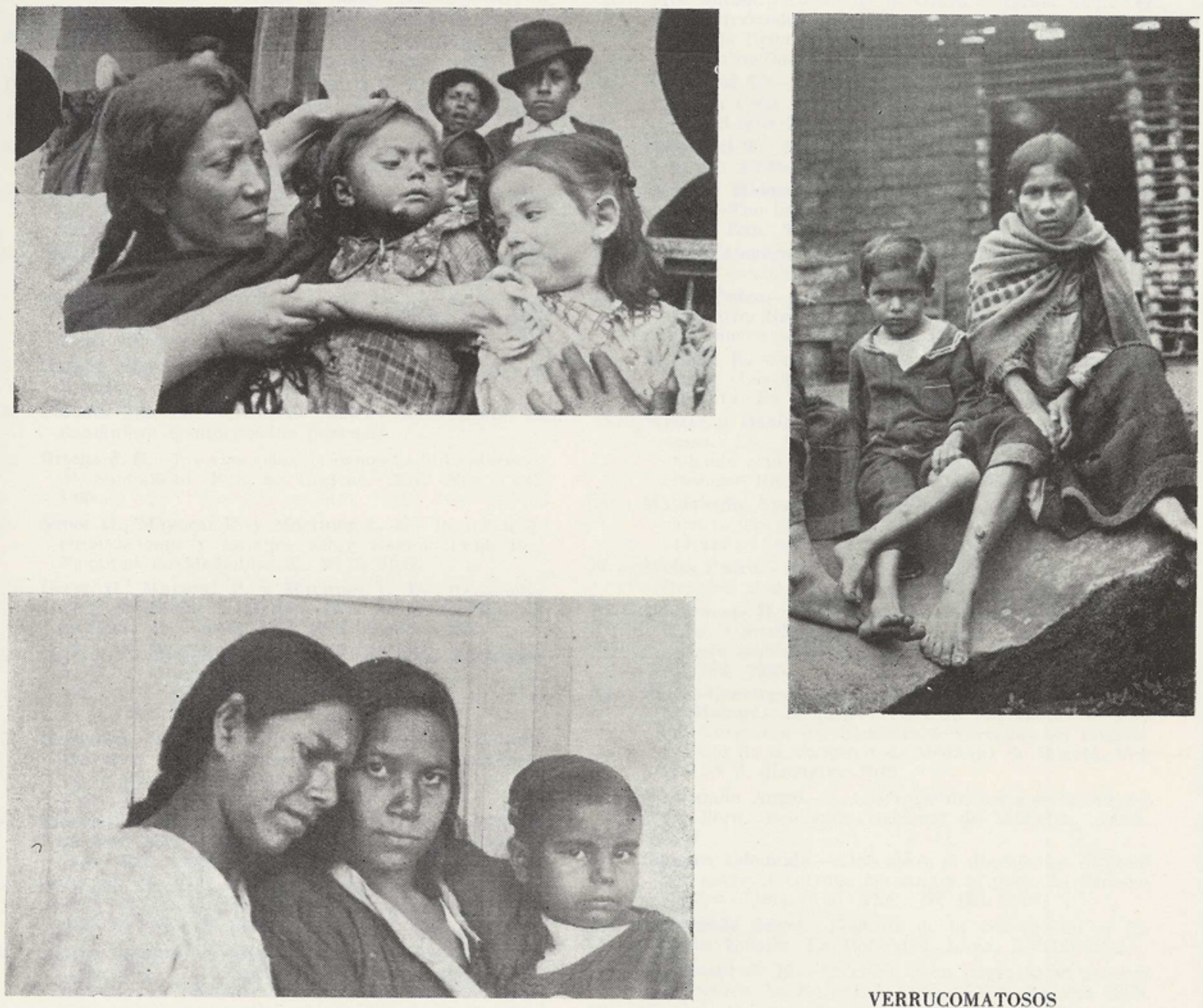

VERRUCOMATOSOS
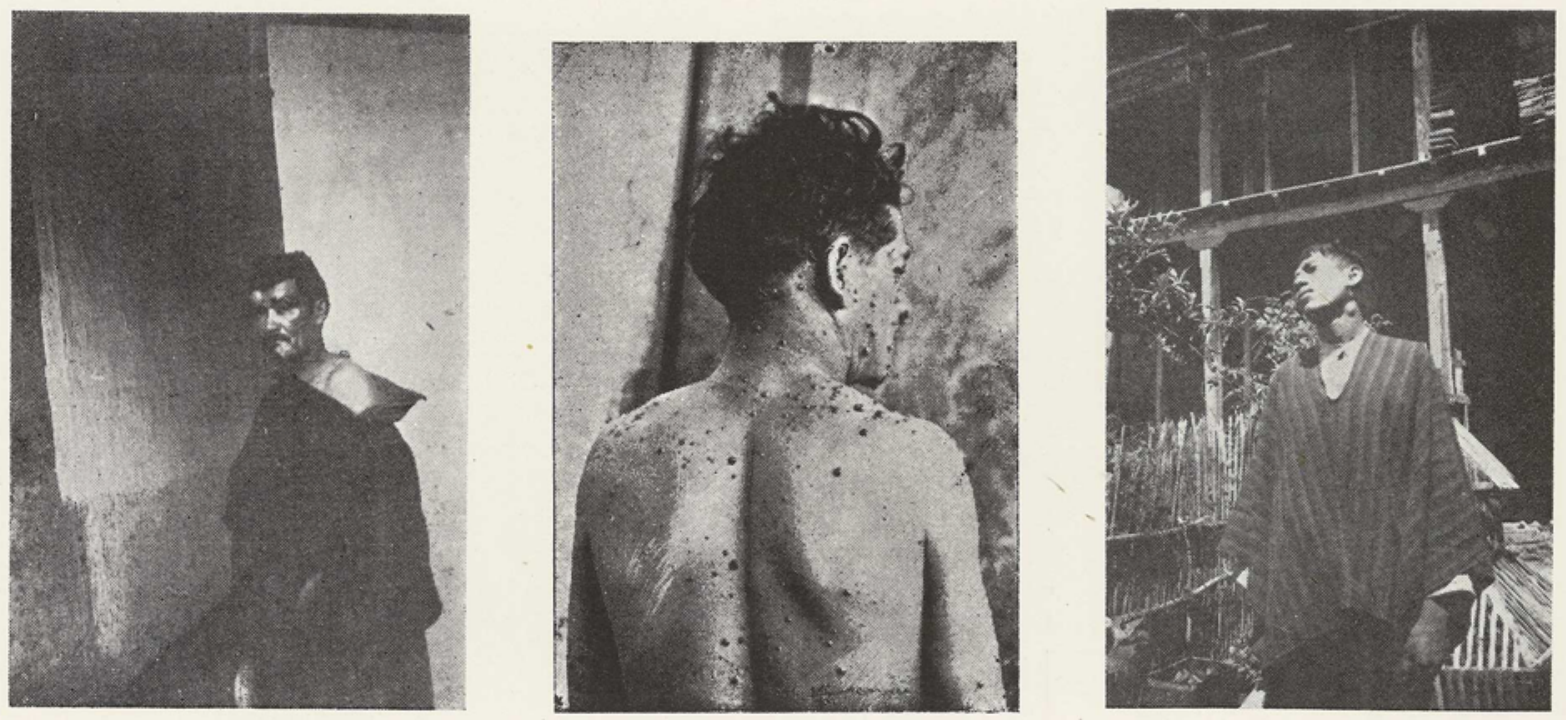
(37) el cloruro de magnesio por vía venosa. Para casos de intensa anemia la transfusión es lo indieado.

En la fase verrucomatosa o histioide la medicación debe consistir únicamente en proteger las verrugas de las infecciones asociadas. La extirpación sólo debe hacerse sobre elementos pediculados. La verruga cura sin dejar huella, cuando no se la mortifica con tratamientos inoportunos.

El calcio y los extractos de órganos son auxiliares de la regeneración hemática. Y la alimentación nutritiva y rica en vitaminas, es lo fundamental.

NOTA.-Hoy están en boga los antibióticos: penicilina, aureomicina $\mathrm{y}$ cloromicetina. La literatura sobre el particular es copiosa.

Profilaxis. - Las fuentes del virus, los agentes vectores $\mathrm{y}$ el hombre en potencia de contaminación, son los factores que no se deben caer de la memoria al hablar de profilaxis de la Bartoneliasis.

Anoté cómo el hombre enfermo es fuente de con. taminación. Pero dije igualmente que esta noción sabida no era suficiente para explicar la endemoepidemia de Nariño y que se hacía preciso indagar en busca de reservorios animales y vegetales, porque los datos allegados no autorizan conclusiones.

Igual cosa puede decirse de vectores. Potencialmente todo hematófago podría ser vector de un virus transmisible. Con las Rickettsias se está viendo cómo aparecen, al buscarlos, nuevos vectores distanciados largamente en la escala zoológica, como los piojos y los Ornithodoros, pongo por caso. Por analogía con lo observado en el Perú, se ha hablado de los flebótomos y por analogía con las rickettsiasis, de los piojos.

Al hombre debe considerársele en la profilaxis, como fuente de virus cuando está enfermo y como terreno propicio para recibir el contagio cuando no es inmune.

El autor, comisionado del Ministerio de Higiene, que hizo en enero de 1939 el diagnóstico de la Bartoneliasis, base de la profilaxis, aconsejó en sus informes (4) medidas que se han aplicado en parte sobre las zonas afectadas, con los siguientes puntos:

a) Hospitalización de todos los casos agudos en hospitales de emergencia urbanos y rurales y en consecuencia organización de uno o dos en cada población afectada. Creación de hospitales definitivos estratégicamente localizados, para la hoya del río Mayo en La Unión, para el Guáitara en Sandoná y para el río Pacual en Samaniego.

b) Campaña con todos los recursos del estado para levantar el nivel de vida del hombre de los campos y poblaciones pequeñas, v. g., con el siguiente esquema:

$1^{\circ}$-Saneamiento de las chozas rurales, oscuras y sucias, con sencillo plan de emergencia: separar de la habitación humana los curíes y demás animales domésticos; independizar la cocina del dormitorio; abrir ventanas y dar aire y sol; empañetar y blan- quear las paredes por dentro $\mathrm{y}$ por fuera; revestir los pisos con ladrillo, cemento o asfalto; hacer un excusado de hoyo.

$2^{\circ}$-Establecer una lucha racional contra ectoparásitos humanos.

$3^{\circ}$-Enseñar a los labriegos técnicas de cultivos intensivos.

$4^{2}$ Disminuír el auge del alcoholismo.

$5^{9}$-Rehabilitar la industria casera de los sombreros jipas, fuente de riqueza y de bienestar de los campesinos nariñenses y causa ahora por su bancarrota de su pobreza y de que la ración alimenticia sea deficiente y paupérrima.

c) Constitución de la asistencia hospitalaria y de las obras sanitarias con amplios recursos nacionales bajo la responsabilidad de un médico que cumpla el viejo aforismo "Suaviter in modo fortiter in re".

Los órganos del Estado han desarrollado en $\mathrm{Na}$ riño una intensa, eficiente $\mathrm{y}$ benéfica labor por medio de los Decretos 331, 1.353 y 1.926 de febrero, junio y septiembre de 1939. Por la aplicación inmediata en Nariño del Decreto-Ley No 200 de 1939, que organiza el Instituto de Crédito Territorial, para el mejoramiento de la vivienda camepsina, fuente, base, colnmna miliar de verdadera profilaxis para las plagas endemoepidémicas que azotan la población rural de nuestra patria. Y finalmente con la Ley $5^{n}$ de 1939 , que ordena hospitales, acueductos y alcantarillados para Nariño y crea el labo. ratorio de Pasto y la campaña contra la Bartonellosis que dirige el doctor Vallecilla.

Resumiendo, considero que la profilaxis debe hacerse hospitalizando y aislando a los enfermos contaminantes y mejorando las defensas orgánicas de los receptivos, y que es indispensable buscar un procedimiento de vacunación.

\section{BIBLIOGRAFIA}

1. Budnik Emilio.-Tifo Exantemático en 1939. Tesis. Santiago de Chile. 1940.

2. Tarassewitsch-Cita de Emilio Budnik.

3. Gordon J. E.-The clinical features of Rickettsial Diseases. Harvard School of Public Health Symposium. Volume 1940.

4. Patiño-Camargo Luis. Informe al doctor Arturo Robledo, encargado del despacho del Ministerio de Higiene. Enero 26 de 1939. Junio 30 1939. Rev. de Hiqiene. XX. Nos. 11-12. Bogotá. 1939.

4. Patiño-Camargo Luis.-Un nuevo foco de Bartonellosis en América. (Nota preliminar). Boletín de la Oficina Sanitaria Panamericana. Año 18 , No 4. Abril 1939.

4. Patiño-Camargo Luis--Bartonellosis en Colombia. Rev. de la Facultad de Medicina. Vol. VII. N 10. Abril 1939.

4. Patiño-Camargo Luis.-Estado actual de la Bartonellosis (Fiebre Verrucosa. Verruga) en el Continente Americano. Vol. IX, No 3, septiembre 1940, Revista de la Facultad de Medicina de Bogotá.

4. Patiño-Camargo Luis-Discurso en la inauguración del Laboratorio Daniel A. Carrión en el Departamento Tropical de la Facultad de Medicina. Bogotá, octubre 5 1941. Rev. de la Frcultad de Medicina, Vol. X. No 5.1941 
5. Rebagliati Raúl.-Verruga peruana (Enfermedad de Carrión), Imp. Torres Aguirre, Lima, 1940.

6. Maldonado Angel-Comunicación presentada a la Academia Nacional de Medicina, Lima, 1931.

7 Sánchez Guillermo.-Historia de la enfermedad de las bubas en Guatemala, Arch. Hosp. Rosales, nbre. 1935 , p. 17.

s. Montalván J. D.-Un foco de bartonellosis en el Ecuador, Bol. Of, San. Pan., fbro. 1940, p. 154

9. Hertig Marshall.-Cultivo de la Bartonella bacilliformis de un caso de verruga peruana en el Ecuador. Bol. Of. San. Pan., agto. 1940 , p. 756 .

10. Otálora Benjamín.-Informe al Ministro de Higiene. Rev. de Higiene. XX. Nos. 11-12. Bogotí. 1939.

11. Jaramillo Raúl.-Contribución al estudio de la Bartonellosis en Colombia (Enfermedad de Carrion). Tesis. Bogotá. Octubre 1939 .

12. Garzón Manuel.-Historias clínicas del Hospital de Ancuya e información personal.

13. Portilla Marcial--Historias clínicas del Hospital de Samaniego e información personal.

14. Ortega J. B.-Informe sobre la campaña antiepidémic: de Samaniego. Rev. de Higiene. Xx. Nos. 11-12 1939

15. Groot H., Mayoral P. y Martínez L. E.-Resumen de observaciones y estudios sobre Bartonellosis. Rev. Facultad de Medicina. X. No 5. 1941.

15 a. Groot H., Mayoral P. y Martínez L. E.-Bartonellosis $y$ fenómeno de Mooser. Rev. de la Facultad de Medicina de Bogotá. IX. No 8. Febrero 1941.

16. Medina C.. Mestanza E., Aree J., Alcedán M., Miranda R. y Montero M.-La Verruga peruana y Daniel A. Carrión. Lima, 1886. Reprod. en An. Fac. Méd. Lima, Nơ extraord. Oet. 1925.

17. Benavides D. Aurelio--Estudio Clínico y Anatomonatológico de las Verrugas y Nódulos subcutáneo de la Bartonellosis humana o Enfermedad de Carrión. Tesis. Bogotá. 1942

18. Ribeyro Ramón E.-Verruga peruana y paratifo B. La Ref. Méd. Lima, Año XVIII. No 149 y en La Crón. Méd. Lima. Año 49. No 834. 1932.

19. Odriozola Ernesto.-La maladie de Carrión ou la Verruga Péruviénne. París. G. Carré et C. Naud, édit. 1898. Citado por Rebagliati.

20. Samper Bernardo y Montoya Juan Antonio.-Estudio bacteriológicos y experimentales de un germen aislado en una epidemia de Bartonellosis en el Departamento de Nariño (Colombia). Rev, de la Facultad de Medicina. Vol. IX. No 4.1940.
21. Arce Julián,-Fiebre de la Oroya o forma aguda de la Enfermedad de Carrión. Tesis de Lima, 1889. Cita de Brumpt, artículo "Verruga du Perou". Nouvelle Practique Dermatologique. Tome IV. 1936.

22. Tewnsend $\mathrm{Ch}$ - L L titira es transmisora de la Verruqa. La Crón. Méd. Lima. XXX. No 588. 1913. (Cita de Rebagliati).

23. Battistini T. - Estudios sobre la Verruga peruana. La Acción Médica. Yima, 5 de enero de 1929.

24. Noguehi Hideyo, Shannon C., Tilden E. B. y Tyler J. E.-The insects rectors of Carrion's Disease. The J. of Exy. Med. 1929.

25 Patiño-Camargo Luis.-Artrópedos hematófagos de la fauma colombiana. Rev. Fac. Med., jul. 1940, p. 23.

26. Weiss Pedro-Sobre las inclusiones encontradas el los eritrocitos de algunas lagartijas (Lacertija sp.) Ina nueva bartonella? An. Fac. Med. Lima, 1927.

27. Fscomel E.-La maladie de Carrion on Verruga du Peron (Les derniéres acquisitions) Bull, de la soc. de Path. Ex. XXXI. No T. 1938 .

28. Weinman David and Henry Pinkerton.-Carrion's Disease. IX. Natural sources of Bartonella in the endemic zone. Proceedings of the Society for Experimental Biology and Medicine, 1937. 37. . 587-600.

29) Maldenado Angel- - Probable "ol de alguuas plantas características de las quebradas verrucógenas $\mathrm{y}$ utógenas. Lima. Perú. Septiembre 1930.

:0. Weiss Pedro.-La verruga reruana y el humarpo. La Crónica Méd. Líma. Año 47. No 810.1930.

31. Mackehenie D. y Coronado D.-Plantas reservorios de virus. Contribución al conocimiento de la fitopatogenesis peruana. La Ref. Méd. Lima. Año XIX. No 162. 1933.

32. Patiño-Camargo L., Cifuentes Plinio y Sánehez-Herrera Manuel.-El primer caso de Bartonellosis (Fiebre Verrucosa del Guáitara o Verruga) en Bogotá. Rerista de la Facultad de Medicina de Bogotá. Vol. IX. No 6, diciembre 1940 .

33. Maldonado Angel. - La berruga de los conquistadores del Perú. Academia Nacional de Medicina. Lima. 1931.

34. Escomel Edmundo.-Algo sobre el diagnóstico diferencial entre la verruga peruana y el pian. La Crónica Médica, Lima. Año XXV. Nơ 476. 1908 .

35. Maldonado Angel.-Folklore de la verruga en el rí Santa Eulalia. La Ref. Méd. Lima. XVIII. 1932.

36. Kuczynski G. M.-El cobre y su papel en el proceso carriónico. La Ref. Méd. Líma. XXIV. No 289. 1938.

37. Bernales Sergio.-An. del Hosp. Lima. III. No 4. 1920 (Cita de Rebagliati). 